\title{
A Relação entre Educação Pré-Primária, Salários, Escolaridade e Proficiência Escolar no Brasil
}

- ANDRÉA ZAITUNE CURI *
- NaÉrcio AQuino MENEZES-FILHo**

\begin{abstract}
RESUMO
Neste artigo analisamos a relação entre a educação pré-primária (creche e pré-escola) e os salários, a escolaridade e a proficiência escolar no Brasil, utilizando dados da PPV e do SAEB. Os resultados mostram que a pré-escola tem uma relação positiva e significante com a conclusão dos quatro ciclos escolares, com efeito marginal crescente nos três primeiros, e que a creche tem relação positiva e significante apenas com a conclusão do ensino médio e do ensino universitário. Além disso, a pré-escola está associada com um aumento de I ano e meio de escolaridade e de $16 \%$ na renda, independentemente da sua relação com a educação. Finalmente, os alunos que frequentaram a pré-escola têm um desempenho escolar melhor, medido por testes de proficiência, na $4^{a}$ e $8^{a}$ séries do ensino fundamental e na $3^{a}$ série do ensino médio.
\end{abstract}

Palavras-CHAVE

creche, pré-escola, ciclos escolares, proficiência escolar, salários

\section{ABSTRACT}

This paper examines the relations between daycare and pre-school, wages, education and school performance in Brazil using a survey with detailed information on education and earnings trajectories. We find that pre-school attendance has a positive relationship with primary, middle school, high school and college conclusion, even when we condition on parental education. Pre-schooling is associated with increases of I.5 year in schooling and about $27 \%$ in wages. Pre-schooling is also associated with increases in standardized test scores in the 4 th, 8 th and I I th grades.

\section{KEYWORDS}

daycare, pre-school, education, school performance, wages

\section{JEL Classification}

120

\footnotetext{
* Tendências Consultoria Integrada. Endereço para contato: Rua Estados Unidos, 498 - Casa - Jardim Paulista - São Paulo - SP. CEP: 01427-000. E-mail: acuri@tendencias.com.br.

* Insper Instituto de Ensino e Pesquisa e FEA/USP. Endereço para contato: Rua Quatá, 300 - Vila Olímpia - São Paulo - SP. CEP: 04546-042. E-mail: naercioamf@insper.org.br.

(Recebido em janeiro de 2008. Aceito para publicação em abril de 2009).
} 


\section{$1 \quad$ INTRODUÇÃO}

Muitos estudos internacionais vêm destacando a importância do investimento em educação pré-primária. A pré-escola visa o desenvolvimento físico, emocional, social e intelectual da criança, objetivando sua autonomia, autocontrole e confiança para se expressar e se comunicar. Pesquisas recentes comprovam que o acesso ao préprimário tem um grande efeito no desempenho dos alunos em testes de proficiência e na habilidade comportamental não cognitiva como atenção, esforço, disciplina, e participação em aula (GARCES et al., 2002; GERTLER; FERNALD, 2004).

Pesquisadores têm constatado que o aprendizado é mais fácil no início da infância do que mais tarde, e que nutrição e estímulos cognitivos no início da vida são fundamentais para o desenvolvimento de habilidades no longo prazo. Segundo Carneiro, Cunha e Heckman (2003), o retorno de investimento em educação nos Estados Unidos é muito maior para idades mais precoces. Os autores mostram que o retorno de investimento em educação é decrescente com a idade, sendo particularmente alto para educação infantil.

Muitos países da OCDE e países de renda média têm tornado a educação pré-primária universal com o objetivo de proporcionar às crianças um começo de vida melhor. A partir de experimentos aleatórios, estudos internacionais têm mostrado que as intervenções no início da infância geram retornos elevados. Nos Estados Unidos, as crianças que foram aleatoriamente beneficiadas com o Perry Preschool Program tiveram alto desempenho em testes de proficiência anos depois, baixas taxas de encarceramento, e rendimentos médios um terço maior do que o do grupo de controle (CURRIE, 2001; CARNEIRO; HECHMAN, 2003). Garces et al. (2002) mostram que os participantes do Head Start apresentaram maior propensão a frequentar a faculdade e menores taxas de delinquência e crime. Da mesma forma, resultados positivos foram obtidos pelo Carolina Abecederian Project (CURRIE, 2001).

Os programas de incentivo ao desenvolvimento infantil na América Latina e no Caribe também apresentam resultados positivos. Beharman, Cheng e Todd (2004) relatam os efeitos do programa de pré-escola na habilidade motora, habilidade físicosocial e aquisição de idiomas na Bolívia. Berlinski e Galiani (2005) e Berlinski et al. (2005) mostram que o programa de construção de pré-escolas na Argentina aumentou as taxas de matrículas na pré-escola, e melhorou o desempenho cognitivo e os resultados comportamentais dos que frequentaram a pré-escola.

No Brasil, existe carência de estudos sobre a importância socioeconômica da educação nos primeiros anos de vida. Por isso, neste artigo procuramos analisar a relação entre a educação pré-primaria e vários indicadores educacionais e socioeconômicos 
no Brasil. Analisamos a relação entre a frequência à creche e à pré-escola e a conclusão dos ciclos escolares, o desempenho escolar medido por testes de proficiência e os salários no Brasil. Consideramos esse estudo importante para o Brasil para mostrar que as políticas públicas que visam reduzir as diferenças sociais por meio de investimentos em educação devem agir desde os primeiros anos de vida, amenizando dificuldades e distorções futuras. Na parte metodológica discutiremos mais detalhadamente os limites deste estudo, em comparação com a literatura internacional (revisada na próxima seção), especialmente em relação à estratégia de identificação.

Além dessa introdução, o trabalho tem mais sete seções. Na segunda seção, fazemos uma revisão aprofundada da bibliografia internacional sobre a relação entre a préescola e o desenvolvimento dos indivíduos, a fim de permitir a consolidação de uma base de conhecimento ampla e diversificada sobre o tema, abordando as diversas perspectivas de análise existentes. Na seção seguinte, apresentamos os dados utilizados. A quarta seção destaca a metodologia econométrica aplicada em cada uma das etapas desse estudo. $\mathrm{Na}$ seção cinco, fazemos uma análise descritiva dos dados e na seção seguinte apresentamos os resultados econométricos obtidos. Por fim, na última seção expomos nossas conclusões.

\section{REVISÃO BIBLIOGRÁFICA ${ }^{1}$}

Em muitos países em desenvolvimento, as crianças sofrem de profundos déficits em nutrição, saúde, habilidade motora, desenvolvimento cognitivo, e desenvolvimento socioemocional. Os resultados do desenvolvimento no início da infância (Early Childhood Development - ECD) são responsáveis pelo bem-estar da criança no futuro. Além disso, os efeitos danosos do desenvolvimento inadequado nas idades iniciais podem ser duradouros, afetando desempenho escolar, emprego, salário, criminalidade, e medidas de integração social de adultos - Schady (2006).

De acordo com a literatura dos Estados Unidos, as crianças de famílias com alta renda e pais de elevado nível educacional têm melhor desempenho em testes cognitivos (BLAU, 1999; TAYLOR et al., 2004) e baixa incidência de problemas comportamentais (BERGER et al., 2005). Essa relação entre a posição socioeconômica e a habilidade infantil também está presente nos países da América Latina (PAXSON; SCHADY, 2005).

1 Muitos dos artigos citados nessa revisão bibliográfica são inéditos, o que decorre, em parte, do fato de os textos serem bastante recentes. Assim, destacamos que esta é uma revisão que contém artigos que ainda não passaram pela avaliação de pareceristas e editores, sendo passíveis de alterações. 
Segundo alguns pesquisadores de países desenvolvidos, o baixo nível de desenvolvimento cognitivo na infância, medido por testes aplicados aos 22 meses de idade é um importante prognóstico dos salários (CURRIE; THOMAS, 1999; ROBERTSON; SYMONS, 2003). Outros autores têm argumentado que a dimensão não cognitiva do desenvolvimento no início da infância é um importante determinante do sucesso futuro (CARNEIRO; HECKMAN, 2003; CUNHA et al., 2005). Assim, ambas, habilidades cognitiva e não cognitiva, podem contribuir para a transmissão da pobreza através das gerações.

Segundo Heckman (2005), a interferência, cedo o suficiente, pode afetar o desenvolvimento dessas duas habilidades, cognitiva e não cognitiva. $\mathrm{O}$ autor, a partir do questionamento de por que a sociedade deve investir em crianças em desvantagem social, argumenta que intervenções iniciais nessas crianças promovem escolaridade, aumentam a qualidade da força de trabalho e a produtividade na escola, e reduzem criminalidade e a gravidez na adolescência.

Cunha et al. (2005) desenvolvem um modelo de formação da habilidade humana. Primeiro, de acordo com os autores, as habilidades são multidimensionais. As habilidades cognitivas e não cognitivas afetam a escolaridade e os salários, sendo que a habilidade cognitiva pura inclui QI e a habilidade não cognitiva inclui paciência, autocontrole, temperamento e preferência temporal. As habilidades são formadas por componentes genéticos e influências ambientais, e a influência dos pais tem particular importância. Segundo, a habilidade é formada por uma tecnologia de múltiplos estágios. Algumas habilidades podem ser produzidas mais eficientemente em um dado período da vida, o qual Cunha $e t$ al. denominam "período sensitivo", e outras habilidades podem apenas ser produzidas em um período particular denominado "período crítico". O período sensitivo ou o período crítico significam que remediar alguma habilidade não adquirida no início da infância é impossível ou extremamente custoso. No caso extremo de uma tecnologia Leontieff, os investimentos em formação de habilidade durante o período de escola ou pós-escola são apenas produtivos se investimentos suficientemente elevados foram feitos anteriormente. Terceiro, existe uma "produtividade própria" na formação de habilidades. Assim, as habilidades adquiridas em um período persistem nos períodos subsequentes, e as habilidades adquiridas em uma dimensão podem facilitar a aquisição de habilidades em outras dimensões. Quarto, existe uma "complementaridade" de habilidades, tal que as habilidades adquiridas em um período aumentam a produtividade de investimentos em idades posteriores. Finalmente, como resultado da produtividade própria e complementaridade, Cunha et al. argumentam que investimentos nas idades iniciais podem ter importantes efeitos multiplicativos (SCHADY, 2006). 
Corroborando essas ideias, vários estudos internacionais analisam os programas governamentais de incentivo ao desenvolvimento infantil em diversos países. A partir de experimentos aleatórios, as crianças são divididas em dois grupos: um grupo de tratamento, que recebe a intervenção governamental, e um grupo de controle. A comparação entre esses dois grupos indica os efeitos da educação infantil no desenvolvimento do indivíduo.

O Perry Preschool Program foi um programa de intervenção pré-escolar implementado nos Estados Unidos. Entre 1962 e 1967, crianças afro-americanas de baixa renda com 3 ou 4 anos de idade foram aleatoriamente denominadas de grupo de tratamento e grupo de controle. O grupo de tratamento recebeu meio dia de pré-escola todos os dias da semana, mais visitas semanais em casa, ambos por oito meses do ano durante dois anos. O projeto coletou informações dos dois grupos estudados entre os 3 e 11 anos de idade, e aos 14, 15, 19, 27 e 40 anos de idade. Os dados obtidos mostraram que, de acordo com as medidas de desempenho educacional, o grupo de tratamento teve resultados melhores do que o grupo de controle. As pessoas tratadas apresentaram baixo grau de repetência, altas taxas de conclusão do colégio, alto desempenho em vários testes intelectuais e de idiomas até os 7 anos de idade, em teste de proficiência aos 9, 10 e 14 anos de idade, e em teste de literatura aos 19 e 27 anos. Aos 40 anos de idade os que receberam intervenção na pré-escola tinham rendimentos médios um terço maior do que os que não receberam, maior probabilidade de estarem empregados, baixa proporção de detenção e foram condenados a menos anos de prisão (CURRIE, 2001; CARNEIRO; HECKMAN, 2003).

O artigo de Heckman (2005) aponta que intervenções realizadas em idades precoces aumentam o QI das crianças durante a vida. O Carolina Abecederian Project investe em crianças em desvantagem social já nos primeiros quatro meses de vida. O efeito do programa persiste mesmo após sua interrupção. As crianças são aleatoriamente introduzidas ao grupo de tratamento, que recebe intensivamente serviços baseados no desenvolvimento de idiomas até os 5 anos de idade, e ao grupo de controle. No início da escola os alunos eram, de novo, aleatoriamente divididos em dois grupos, um que não recebia intervenção, e outro que recebia uma "Home School Resource Teacher". Aos 15 anos, as crianças que receberam a intervenção pré-escolar obtiveram notas maiores em testes de proficiência, e menor incidência de reprovação. Por outro lado, o efeito do Home School Resource Teacher foi pequeno ou não significante. Aos 21 anos as crianças expostas à intervenção do Abecederian tiveram maiores notas em médias, e apresentaram probabilidade duas vezes maior de continuar os estudos ou ingressar no quarto ano da faculdade do que as crianças do grupo de controle (SCHADY, 2006). 
Em 1965, a administração Johnson criou o Head Start. O programa fornecia às crianças em condições inferiores acesso à pré-escola. As crianças beneficiadas pelo Head Start apresentaram maior probabilidade de progredir adequadamente nos estudos, menor taxa de abandono do colégio, e nota em testes significantemente maiores. Além disso, os estudos sobre os impactos do programa mostraram que, entre os brancos, os beneficiados pelo programa obtiveram maiores taxas de ingresso na universidade, e, entre os negros, os indivíduos que tiveram acesso à pré-escola apresentaram menores taxas de delinquência e criminalidade (GARCES et al., 2002).

Na América Latina também foram implementados programas de desenvolvimento infantil. Gertler e Fernald (2004) analisam o impacto do Oportunidades, um projeto implantado no México para combater a pobreza, visando diminuir a miséria em comunidades rurais. As crianças beneficiadas pelo programa são imunizadas, seu crescimento é monitorado e a elas são dados suplementos alimentares, os pais recebem educação em saúde, nutrição e higiene. Os autores observaram significantes diferenças na habilidade motora entre os grupos de tratamento e de comparação. Em média, os resultados são 15 por cento maior entre os homens e 10 por cento maior entre as mulheres na comunidade tratada do que entre crianças similares na comunidade de comparação. As crianças da comunidade tratada apresentaram menos problemas socioemocionais, apesar de o efeito ser significante apenas entre as meninas. Behrman, Cheng e Todd (2004) focam nos resultados de escolaridade das crianças expostas ao Oportunidades durante seus anos de pré-escola. Os autores mostram que as crianças beneficiadas pelo programa entre os 0 e 6 anos de idade tiveram maior probabilidade de ingressar na escola e progredir nos estudos.

Três artigos recentes analisam os impactos da pré-escola na Bolívia e na Argentina. Behrman, Cheng e Todd (2004) usam dados não experimentais para analisar o impacto do programa de pré-escola na Bolívia, o Proyecto Integral de Desarrollo Infantil (PIDI). Comparando os grupos de tratamento e de controle, os resultados mostram impactos positivos do programa na habilidade motora, habilidade psicossocial, e aquisição de idiomas. Esses impactos estão concentrados em crianças com 37 meses ou mais de idade; para crianças mais novas, de 6 a 36 meses, os impactos estimados do programa não são significantes. Os autores também calculam o custo-benefício do programa e obtiveram resultado positivo.

O artigo de Berlinski e Galiani (2005) analisa o impacto da construção da pré-escola na Argentina nos anos 90 que teve como objetivo aumentar o acesso à escola de crianças entre 3 e 5 anos de idade. O governo argentino iniciou um programa de construção de pré-escolas públicas em larga escala. 
De acordo com os resultados obtidos, as taxas de matrículas na pré-escola no período de 1991 a 2001 aumentaram consideravelmente. As estimações de Berlinski, Galiani e Gertler, de 2006, sugerem que metade dos 15 pontos percentuais de aumento da taxa de matrícula deveu-se ao programa. Com relação ao desempenho escolar, seus resultados mostram que o acesso à escola pré-primária teve um efeito positivo no desempenho em testes de matemática e de espanhol no $3^{\circ}$ grau. As estimações implicam que um ano de pré-escola aumenta o desempenho em $8 \%$ da média e em $23 \%$ do desvio padrão da distribuição da nota do teste (BERLINSKI; GALIANI; GERTLER, 2006). Além disso, eles encontraram um grande efeito positivo da educação pré-primária na habilidade comportamental dos estudantes da $3^{\mathrm{a}}$ série como atenção, esforço, participação em aula e disciplina. Esses efeitos positivos na habilidade comportamental fornecem evidências do possível caminho pelo qual o pré-primário afeta o posterior desempenho em testes na escola primária, como a educação pré-escolar facilita o processo de socialização e autocontrole necessários para obter o melhor do aprendizado em aula (CURRIE, 2001). Para o Brasil, pouco se estudou sobre o assunto. Assim, este artigo procura preencher esta lacuna.

\section{DADOS}

Os dados que utilizamos neste trabalho provêm de duas fontes distintas. Uma delas é a Pesquisa de Padrão de Vida (PPV), realizada pelo Instituto Brasileiro de Geografia e Estatística - IBGE, entre março de 1996 e março de 1997, nas regióes do Nordeste e do Sudeste do Brasil. A outra fonte é o Sistema Nacional de Avaliação da Educação Básica (SAEB), realizado em 2003 em todo o Brasil pelo Instituto Nacional de Estudos e Pesquisas Educacionais Anísio Teixeira - INEP, órgão do Ministério da Educação.

A PPV é uma pesquisa domiciliar que foi realizada no Brasil em convênio com o Banco Mundial nas regióes do Nordeste e do Sudeste. O objetivo da pesquisa foi aprimorar o sistema das estatísticas socioeconômicas, através da obtenção de informações que qualifiquem e indiquem os determinantes do bem-estar social de diferentes grupos sociais e que permitam identificar os efeitos de políticas governamentais nas condições de vida domiciliar. Um dos temas apurados pela pesquisa foi a Educação.

A fim de analisar a relação entre o pré-primário (creche e pré-escola), os salários e a educação futuros restringimos a amostra da PPV aos indivíduos das coortes de 1932 a 1974 que tinham entre 21 e 65 anos de idade no ano da pesquisa. 
O Sistema Nacional de Avaliação da Educação Básica é a primeira iniciativa brasileira no sentido de conhecer mais profundamente o nosso sistema educacional. Esta avaliação vem sendo aplicada desde 1990. Em 2003, participaram do SAEB cerca de 300 mil alunos, 17 mil professores e 6 mil diretores de 6.270 escolas das 27 Unidades da Federação. Como o SAEB não avalia, ainda, a totalidade dos estudantes do País, a pesquisa é feita em uma amostra que representa o universo das matrículas. As informações obtidas a partir dos levantamentos do SAEB permitem acompanhar a evolução da qualidade da educação ao longo dos anos. Participam da avaliação alunos da $4^{\mathrm{a}}$ e da $8^{\mathrm{a}}$ séries do ensino fundamental e da $3^{\mathrm{a}}$ série do ensino médio, que fazem provas de Língua Portuguesa e de Matemática. Eles também respondem a um questionário sobre seus hábitos de estudo e suas características socioculturais. Os professores e os diretores participam respondendo a questionários que informam sobre perfil e prática docentes, mecanismos de gestão e infraestrutura escolar.

A fim de analisar a relação entre a pré-escola e o desempenho escolar, medido por testes de proficiência, utilizamos os resultados obtidos pelos alunos da $4^{\mathrm{a}}$ e da $8^{\mathrm{a}}$ séries do ensino fundamental e da $3^{\mathrm{a}}$ série do ensino médio nos exames de matemática realizados em 2003.

\section{METODOLOGIA ECONOMÉTRICA ${ }^{2}$}

Com o objetivo de estudar a importância da creche e da pré-escola no desenvolvimento dos indivíduos fazemos três análises econométricas. Na primeira delas estimamos a relação entre a educação pré-primária e a conclusão dos ciclos escolares. Isto é, verificamos se o fato de o aluno ter frequentado o pré-primário (iniciados os estudos entre 0 e 6 anos de idade) aumenta a probabilidade de ele concluir o ensino fundamental 1 , o ensino fundamental 2, o ensino médio, e o ensino universitário. Concentramos a segunda análise na relação entre a pré-escola e os salários futuros dos indivíduos. Na terceira análise focamos na importância da pré-escola no desempenho escolar dos alunos medido por testes de proficiência.

Esse estudo apresenta limitações em comparação com a literatura internacional revisada na seção 2, especialmente em relação à estratégia de identificação. Enquanto muitos dos estudos internacionais utilizam experimentos aleatórios, com grupos de controle versus tratamento explícitos ou variação exógena em função de implementação diferenciada do tratamento segundo região e/ou coortes, este estudo usa apenas o controle por observáveis como estratégia de identificação, numa base de dados

2 O programa econométrico Stata foi usado para rodar todas as regressões descritas neste artigo. 
em cross-section. Isso ocorre devido à falta de dados comparáveis aos dos estudos internacionais.

É possível argumentar que, condicionalmente a todos os controles incluídos nas diferentes estimações, pais que se preocupam mais com educação poderiam não apenas matricular seus filhos na pré-escola, como também dar mais atenção à educação dos filhos ao longo dos anos subsequentes, quando estivessem na escola. Além disto, pode ser que as crianças com melhores habilidades cognitivas, independente da educação pré-primária, tenham maior probabilidade de frequentar a creche ou a préescola, uma vez que os pais percebem tais características. Se isto for verdade, essas crianças teriam maior sucesso na conclusão dos ciclos escolares, proficiência e renda independente da educação pré-primária, e assim, os resultados encontrados seriam, então, viesados. Uma solução para tal problema seria a construção de uma variável instrumental que fosse correlacionada com a frequência pré-escolar e que só afetasse as variáveis dependentes através da educação pré-primária. Infelizmente, as bases de dados escolhidas deixam poucas alternativas para a construção desse instrumento.

\subsection{Relação entre a Educação Pré-Primária e a Conclusão dos Ciclos Escolares}

Essa parte do estudo analisa a relação entre a educação pré-primária e a conclusão do ensino fundamental 1 , do ensino fundamental 2 , do ensino médio e do ensino universitário. Para tanto, utilizando os dados da PPV realizada nas regiões do Nordeste e do Sudeste do Brasil. Restringimos a amostra aos indivíduos que nasceram nos anos de 1932 a 1974, e estimamos, para cada um dos ciclos separadamente, um modelo de escolha discreta em que a variável dependente é uma variável binária que indica se o indivíduo concluiu ou não o ensino fundamental 1 , o ensino fundamental 2, o ensino médio, e o ensino universitário.

$\operatorname{Pr}\left(y_{\text {ciclo }}=1 \mid \chi\right)=G\left(\beta_{0}+\beta_{1} x_{1}+\beta_{2} x_{2}+\ldots+\beta_{k} x_{k}\right)=G\left(\beta_{0}+\chi \beta\right)$ em que $G$ é uma função de distribuição acumulada que assume valores entre zero e um: $0<G(z)<1$ para qualquer $z$.

O modelo de escolha discreta estimado foi o modelo Logit, em que $G$ é uma função logística:

$$
\begin{aligned}
& G(z)=\frac{\exp (z)}{1+\exp (z)}=\Lambda(z) \\
& G(z)=\operatorname{Pr}(y=1 \mid \chi)=G(\chi \beta)
\end{aligned}
$$


O efeito parcial das variáveis na probabilidade de resposta é obtido pela derivada parcial:

$$
\frac{\partial p(\chi)}{\partial x_{j}}=g\left(\beta_{0}+\chi \beta\right) \beta_{j} \text { em que } g(z) \equiv \frac{d G}{d z}(z)
$$

As variáveis binárias $y_{\text {ciclo }}$ indicam o ciclo concluído:

Ensino Fundamental $1\left\{\begin{array}{l}1, \text { se } 4 \text { ou mais anos de estudo } \\ 0, \text { caso contrário }\end{array}\right.$

Ensino Funadmental $2\left\{\begin{array}{l}1, \text { se } 8 \text { ou mais anos de estudo } \\ 0, \text { caso contrário }\end{array}\right.$

Ensino Médio $\left\{\begin{array}{l}1, \text { se } 11 \text { ou mais anos de estudo } \\ 0, \text { caso contrário }\end{array}\right.$

Ensino Universitário $\left\{\begin{array}{l}1, \text { se } 15 \text { ou mais anos de estudo } \\ 0, \text { caso contrário }\end{array}\right.$

Para identificar a relação entre a educação pré-primária e a conclusão desses ciclos utilizamos como variável explicativa duas variáveis binárias. A variável Creche, que assume valor 1 , se o indivíduo iniciou os estudos quando tinha entre 0 e 3 anos de idade, e 0 caso contrário, e a variável Pré-escola que assume valor 1 , se o indivíduo iniciou os estudos no pré-primário, entre 4 e 6 anos de idade, e 0 caso contrário.

Creche $\left\{\begin{array}{l}1, \text { se iniciou os estudos entre } 0 \text { e } 3 \text { anos de idade } \\ 0 \text {, caso contrário }\end{array}\right.$

Pré-escola $\left\{\begin{array}{l}1, \text { se iniciou os estudos entre os } 4 \text { e } 6 \text { anos de idade } \\ 0 \text {, caso contrário }\end{array}\right.$

Além dessas variáveis, julgamos relevantes na conclusão dos ciclos escolares algumas características dos indivíduos. Inserimos ao modelo as variáveis que identificam raça, sexo, idade, idade em que começou a trabalhar, se vivia com a mãe aos 15 anos de idade, se a mãe trabalhava quando a pessoa tinha 15 anos de idade e a educação dos pais. A área e o local de moradia também foram considerados no modelo. 
O primeiro conjunto de variáveis refere-se às características individuais. As variáveis sexo e raça controlam os modelos pelas diferenças existentes entre homens e mulheres, e entre as raças, brancos e outros. Com relação à idade, essa variável visa captar as mudanças ocorridas entre as gerações e as diferenças entre as coortes, tanto em termos de alimentação, como em termos de infraestrutura educacional, políticas educacionais no Brasil e exigências do mercado de trabalho. Por fim, a variável idade em que começou a trabalhar identifica os jovens que precisaram, ou optaram, por iniciar no mercado de trabalho mais cedo, isto é, aqueles que estudavam e trabalhavam, o que pode influenciar na conclusão dos ciclos escolares.

O segundo grupo de variáveis indica o background familiar e o ambiente familiar vivenciado pelo indivíduo. O background familiar é representado pela educação dos pais, que apresenta forte influência sobre o desenvolvimento futuro dos filhos. Filhos de pais mais educados são, em média, mais educados, alimentam-se melhor, têm acesso a melhores condições de infraestrutura e saúde. Já o ambiente familiar indica se o indivíduo contou com a presença materna na adolescência. Para tanto, utilizamos duas variáveis: uma indica se a mãe trabalhava quando o jovem tinha 15 anos de idade, e a outra se o jovem vivia com a mãe aos 15 anos de idade. Acreditamos que a presença materna estimular os estudos dos jovens e indica um ambiente familiar mais estável. Assim, todas essas variáveis caracterizam a infância dos indivíduos e vão ser importantes para determinar seu desenvolvimento educacional e profissional. Por fim, o último conjunto de variáveis indica o local e a área de moradia. Essas são importantes para captar os efeitos específicos de cada região. Acreditamos que a introdução dessas variáveis possa diminuir um possível viés de variável omitida que tornaria a parâmetro estimado das nossas variáveis de interesse, "pré-escola" e "creche", inconsistente.

$\operatorname{Pr}\left(y_{\text {ciclos }}=1 \mid \chi\right)=G\left(\beta_{0}+\beta_{1}\right.$ Creche $+\beta_{2}$ Pré-escola $+\beta_{3}$ Sexo $+\beta_{4}$ Raça $+\beta_{5}$ Idade + $\beta_{6}$ Idade ${ }^{2}+\beta_{7}$ Educação_mãe $+\beta_{8} E$ Educação_pai $+\beta_{9}$ Idade_1 ${ }^{\circ}$ Trabalho + $\beta_{10}$ Mãe_trabalhava $+\beta_{11}$ Vivia_mãe $+\beta_{12}$ Area $+\beta_{13}$ Local $)$

Concluímos a análise com uma regressão pelo método de Mínimos Quadrados, tendo como variável dependente os anos de estudo (variável contínua) e como variáveis explicativas as mesmas usadas no modelo Logit para os ciclos.

$$
\begin{aligned}
& Y_{\text {anos de estudo }}=\alpha_{0}+\alpha_{1} \text { Creche }+\alpha_{2} \text { Pré-escola }+\alpha_{3} \text { Sexo }+\alpha_{4} \text { Raça }+\alpha_{5} \text { Idade }+ \\
& \alpha_{6} I d a d e^{2}+\alpha_{7} E \text { ducação_mãe }+\alpha_{8} E d u c a c ̧ \tilde{a} o \_p a i+\alpha_{9} I d a d e \_1^{\circ} \text { Trabalho }+ \\
& \alpha_{10} \text { Mãe_trabalhava }+\alpha_{11} \text { Vivia_mãe }+\alpha_{12} \text { Area }+\alpha_{13} \text { Local }+\varepsilon
\end{aligned}
$$




\subsection{Relação entre a Educação Pré-Primária e o Salário}

A segunda análise desse estudo é a relação entre a educação pré-primária e o salário futuro. Para tanto utilizamos novamente os dados da Pesquisa de Padrão de Vida com informações sobre os indivíduos das coortes de 1932 a 1974.

Estimamos o modelo através do método de Mínimos Quadrados, tendo como variável dependente o logaritmo da renda do trabalho principal, e como variáveis explicativas as variáveis binárias Creche e Pré-escola, e as variáveis relacionadas às diversas características dos indivíduos. Inserimos ao modelo as variáveis de raça, sexo, idade, nível educacional e idade em que começou a trabalhar, além de educação dos pais, área e local de moradia, pelos motivos destacados anteriormente.

$\log (\text { Renda })_{\mathrm{i}}=\gamma_{0}+\gamma_{1}$ Creche $+\gamma_{2}$ Pré-escola $+\gamma_{3}$ Sexo $+\gamma_{4}$ Raça $+\gamma_{5}$ Idade + $\gamma_{6}$ Idade ${ }^{2}+\gamma_{7} E d u c a c ̧ \tilde{a} o+\gamma_{8} E d u c a c ̧ \tilde{a} o \_m a \tilde{e}+\gamma_{9} E d u c a c ̧ a \tilde{a} o \_p a i+$

$\gamma_{10} I d a d e \_1{ }^{\circ}$ Trabalho $+\gamma_{11}$ Mãe_trabalhava $+\gamma_{12}$ Vivia_mãe +

$\gamma_{13}$ Área $+\gamma_{14}$ Local $+\eta$

\subsection{Relação entre a Educação Pré-Primária e o Desempenho Escolar (proficiência)}

A partir dos dados do SAEB realizado em 2003, analisamos a relação entre a educação pré-primária e o desempenho escolar dos alunos, medido por exames de proficiência. Pelo método de Mínimos Quadrados Ordinários, estimamos as notas obtidas pelos alunos nos exames de proficiência em função de quando eles começaram os estudos, das suas características, das características dos professores, dos diretores e das escolas.

Fizemos as estimações separadamente para os alunos da $4^{a}$ série e da $8^{a}$ série do ensino fundamental e da $3^{\mathrm{a}}$ série do ensino médio que fizeram as provas de proficiência em matemática.

$\log (\text { Profic })_{i, s}=\gamma+\theta_{1}$ Começou $+\theta_{2} A+\theta_{3} P+\theta_{4} D+\theta_{5} E+\theta_{6} U F+v$

Em que i representa os indivíduos, $s$ a série do aluno, A é o vetor de características dos alunos, P, D e E são os vetores de características dos professores, dos diretores, e das escolas, respectivamente.

A variável Começou identifica quando o aluno iniciou os estudos: na pré-escola (que considera creche e pré-escola), e na $1^{\mathrm{a}}$ série, $2^{\mathrm{a}}$ série ou $3^{\mathrm{a}}$ série do Ensino Fundamental (grupo de comparação). 
Além dessa característica, também consideramos relevantes para determinar o desempenho dos alunos no exame de proficiência os hábitos de estudo e as características sócio-culturais dos mesmos. Inserimos nas estimações as variáveis de sexo, raça e idade dos alunos, uma variável que identifica se o aluno tem computador com internet em casa e outra se ele tem computador sem internet em casa. Consideramos também se ele mora com a mãe, o nível educacional de seus pais e a Unidade da Federação onde fez a prova do SAEB. Por fim, explicamos o modelo pelo perfil escolar do aluno, isto é, se ele já foi reprovado alguma vez, sua postura diante das liçóes de casa, e o tipo de escola que frequenta, pública ou particular. Sobre os professores e os diretores julgamos relevantes as informações sobre o nível educacional, o tempo no magistério e os salários desses profissionais. Com relação às escolas, utilizamos as variáveis que indicam se as escolas possuem ou não computadores, internet, laboratórios, e se aplicam algum programa de redução das taxas de reprovação ou algum programa de redução das taxas de abandono.

\section{ANÁLISE DESCRITIVA}

Segundo as informações da PPV coletadas nas regiões Nordeste e Sudeste do Brasil entre março de 1996 e março de 1997, das pessoas com idade entre 21 e 65 anos, menos de $1 \%$ iniciaram os estudos quando tinham de 0 a 3 anos de idade (fizeram Creche), e 17,4\% delas começaram a frequentar a escola entre 4 e 6 anos de idade (fizeram Pré-escola).

A Figura 1 mostra a porcentagem de indivíduos que frequentaram creche ou préescola (entre 0 e 6 anos de idade) por coorte de nascimento. Verificamos que a porcentagem de frequência à creche/pré-escola tem aumentado ao longo dos anos. Em média, menos de 5\% dos que nasceram nos anos 30 e 40 frequentaram creche/ pré-escola, enquanto dos que nasceram nos anos 50 essa porcentagem é de $10 \%$ e dos que nasceram nos anos 60 é de $22 \%$. Por fim, entre os que nasceram em 1974, mais de $40 \%$ frequentaram creche/pré-escola. 
FIGURA I - EVOLUÇÃO DA PORCENTAGEM DE PESSOAS QUE FIZERAM CRECHE OU PRÉ-ESCOLA POR ANO DE NASCIMENTO

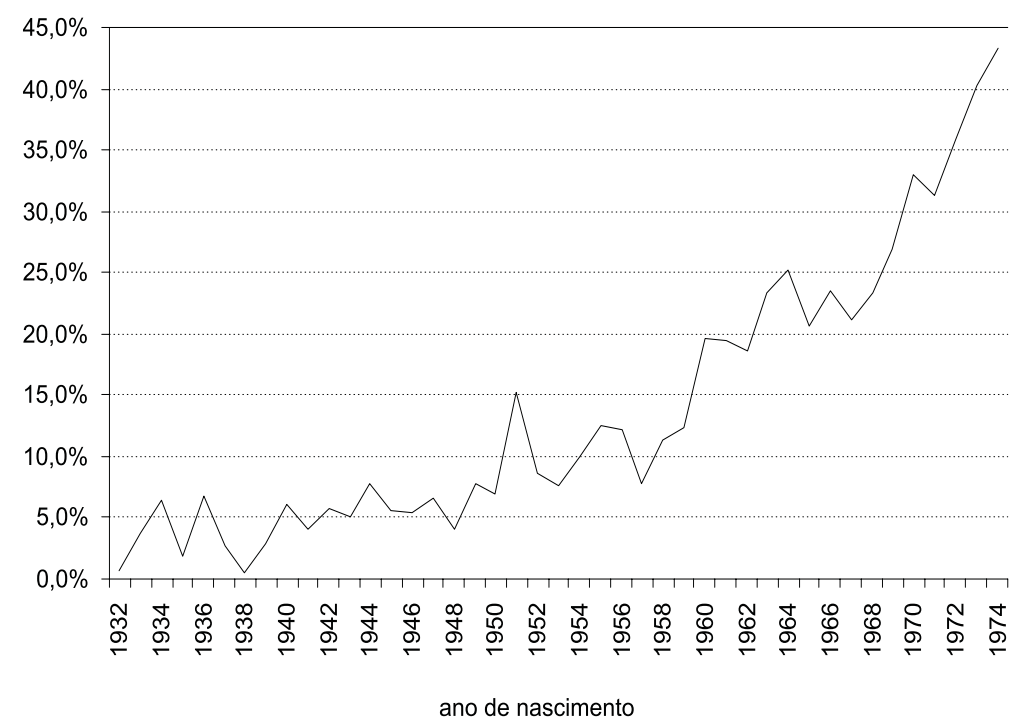

Fonte: PPV. Elaboração própria.

TABELA 1 - PORCENTAGEM DE PESSOAS QUE COMEÇARAM A ESTUDAR NO PRÉ-PRIMÁRIO POR ANO DE NASCIMENTO

\begin{tabular}{|c|c|c|c|c|c|}
\hline \multicolumn{2}{|c|}{$4^{\mathrm{a}}$ série do E.F. } & \multicolumn{2}{|c|}{$8^{\text {a }}$ série do E.F. } & \multicolumn{2}{|c|}{$3^{\mathrm{a}}$ série do E.M. } \\
\hline $\begin{array}{c}\text { Ano de } \\
\text { Nascimento }\end{array}$ & $\begin{array}{l}\text { Início dos } \\
\text { estudos } \\
\text { Pré-escola }\end{array}$ & $\begin{array}{c}\text { Ano de } \\
\text { Nascimento }\end{array}$ & $\begin{array}{l}\text { Início dos } \\
\text { estudos } \\
\text { Pré-escola }\end{array}$ & $\begin{array}{c}\text { Ano de } \\
\text { Nascimento }\end{array}$ & $\begin{array}{l}\text { Início dos } \\
\text { estudos } \\
\text { Pré-escola }\end{array}$ \\
\hline 1988 ou antes & $46,3 \%$ & 1984 & $54,8 \%$ & 1981 & $65,1 \%$ \\
\hline 1989 & $51,1 \%$ & 1985 & $66,0 \%$ & 1982 & $65,5 \%$ \\
\hline 1990 & $61,1 \%$ & 1986 & $67,3 \%$ & 1983 & $71,9 \%$ \\
\hline 1991 & $62,4 \%$ & 1987 & $74,6 \%$ & 1984 & $72,7 \%$ \\
\hline 1992 & $77,1 \%$ & 1988 & $83,5 \%$ & 1985 & $85,4 \%$ \\
\hline 1993 & $84,1 \%$ & 1989 & $87,3 \%$ & 1986 & $84,9 \%$ \\
\hline 1994 & $80,2 \%$ & 1990 & $84,1 \%$ & 1987 & $85,5 \%$ \\
\hline Total & $76,0 \%$ & Total & $80,1 \%$ & Total & $79,8 \%$ \\
\hline
\end{tabular}

Fonte: SAEB, 2003. Elaboração própria.

A partir dos questionários sobre as características dos alunos que fizeram a prova de matemática do SAEB em 2003, a Tabela 1 mostra a porcentagem de alunos da $4^{\mathrm{a}}$ série do ensino fundamental, da $8^{\mathrm{a}}$ série do ensino fundamental e da $3^{\mathrm{a}}$ série do ensino médio que começaram a estudar na pré-escola, por ano de nascimento. De 
acordo com os dados, a porcentagem de alunos que fizeram o pré-primário aumenta entre os mais jovens. Isso mostra que a frequência à pré-escola está se tornando mais comum nos últimos anos. Entre os alunos da $4^{\mathrm{a}}$ série do ensino fundamental, menos de $50 \%$ dos que nasceram até 1988 começaram os estudos na pré-escola, enquanto mais de $80 \%$ dos que nasceram em 1994 frequentaram a educação pré-primária. Entre os alunos da $8^{a}$ série do ensino fundamental, a porcentagem de frequência à pré-escola aumentou mais de 53\%. Quase 55\% dos que nasceram em 1984 foram para a pré-escola, enquanto $84 \%$ dos que nasceram em 1990 começaram na escola antes da $1^{a}$ série do ensino fundamental. Evolução semelhante ocorre entre os alunos da $3^{\mathrm{a}}$ série do ensino médio.

A Tabela 2 mostra, separadamente para alunos da $4^{\mathrm{a}}$ e da $8^{\mathrm{a}}$ séries do ensino fundamental e da $3^{a}$ série do ensino médio, a relação entre o nível escolar da mãe e a frequência à creche e à pré-escola. De acordo com os dados do SAEB realizado em 2003, quanto mais elevada a escolaridade da mãe, maior a porcentagem de crianças que iniciaram os estudos na creche e na pré-escola. Entre os alunos da $4^{\mathrm{a}}$ série do ensino fundamental, menos de $50 \%$ dos filhos de mães que nunca estudaram iniciaram os estudos na pré-escola, enquanto mais de $90 \%$ dos filhos de mães com superior completo começaram a frequentar a escola na pré-escola. Com relação aos alunos da $8^{\mathrm{a}}$ série do ensino fundamental, $95 \%$ daqueles cuja mãe tem superior completo frequentaram a pré-escola, já dos filhos de mãe que não completou nem a $4^{\text {a }}$ série do ensino fundamental, $65 \%$ fizeram a pré-escola. O mesmo ocorre com os alunos da $3^{\text {a }}$ série do ensino médio. Quase $90 \%$ dos filhos de mães com ensino médio completo frequentaram a pré-escola, enquanto $56,3 \%$ dos filhos de mães que nunca estudaram iniciaram os estudos na pré-escola. As informações dessa tabela estão de acordo com os argumentos internacionais sobre a importância da família na educação infantil. 
TABELA 2 - PORCENTAGEM DE PESSOAS QUE COMEÇARAM A ESTUDAR NO PRÉ-PRIMÁRIO POR ESCOLARIDADE DA MÃE

\begin{tabular}{|c|c|c|c|c|c|c|}
\hline \multirow[b]{2}{*}{$\begin{array}{l}\text { Escolaridade } \\
\text { da Mãe }\end{array}$} & \multicolumn{2}{|c|}{$\begin{array}{l}4^{\mathrm{a}} \text { série do E.F. } \\
\text { Início dos estudos }\end{array}$} & \multicolumn{2}{|c|}{ 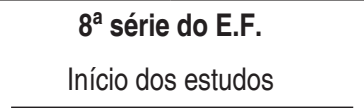 } & \multicolumn{2}{|c|}{$\begin{array}{l}3^{\mathrm{a}} \text { série do E.M. } \\
\text { Início dos estudos }\end{array}$} \\
\hline & Pré-escola & $\begin{array}{l}1^{\mathrm{a}}, 2^{\mathrm{a}} \text { ou } 3^{\mathrm{a}} \\
\text { série do } \mathrm{E} . \mathrm{F} .\end{array}$ & Pré-escola & $\begin{array}{l}1^{\mathrm{a}}, 2^{\mathrm{a}} \text { ou } 3^{\mathrm{a}} \\
\text { série do E.F. }\end{array}$ & Pré-escola & $\begin{array}{l}1^{\mathrm{a}}, 2^{\mathrm{a}} \text { ou } 3^{\mathrm{a}} \\
\text { série do E.F. }\end{array}$ \\
\hline $\begin{array}{l}\text { Nunca } \\
\text { estudou }\end{array}$ & $49,2 \%$ & $50,8 \%$ & $58,4 \%$ & $41,6 \%$ & $56,3 \%$ & $43,7 \%$ \\
\hline $\begin{array}{l}\text { Não } \\
\text { completou a } \\
\text { 4ํ série }\end{array}$ & $63,4 \%$ & $36,6 \%$ & $64,6 \%$ & $35,4 \%$ & $67,0 \%$ & $33,0 \%$ \\
\hline $\begin{array}{l}\text { Completou a } \\
4^{\text {a }} \text { série }\end{array}$ & $73,2 \%$ & $26,8 \%$ & $73,5 \%$ & $26,5 \%$ & $70,2 \%$ & $29,8 \%$ \\
\hline $\begin{array}{l}\text { Não } \\
\text { completou a } \\
\text { 8a série }\end{array}$ & $76,9 \%$ & $23,1 \%$ & $81,0 \%$ & $19,0 \%$ & $79,4 \%$ & $20,6 \%$ \\
\hline $\begin{array}{l}\text { Completou a } \\
8^{\text {a }} \text { série }\end{array}$ & $77,8 \%$ & $22,2 \%$ & $85,1 \%$ & $14,9 \%$ & $81,9 \%$ & $18,1 \%$ \\
\hline $\begin{array}{l}\text { Não } \\
\text { completou o } \\
\text { ensino médio }\end{array}$ & $89,9 \%$ & $10,1 \%$ & $89,8 \%$ & $10,2 \%$ & $85,6 \%$ & $14,4 \%$ \\
\hline $\begin{array}{l}\text { Completou o } \\
\text { ensino médio }\end{array}$ & $86,7 \%$ & $13,3 \%$ & $89,9 \%$ & $10,1 \%$ & $89,6 \%$ & $10,4 \%$ \\
\hline $\begin{array}{l}\text { Não } \\
\text { completou a } \\
\text { faculdade }\end{array}$ & $89,2 \%$ & $10,8 \%$ & $92,3 \%$ & $7,7 \%$ & $93,6 \%$ & $6,4 \%$ \\
\hline $\begin{array}{l}\text { Completou a } \\
\text { faculdade }\end{array}$ & $91,6 \%$ & $8,5 \%$ & $95,0 \%$ & $5,0 \%$ & $94,7 \%$ & $5,3 \%$ \\
\hline
\end{tabular}

Fonte: SAEB, 2003. Elaboração própria.

Na Figura 2, fazemos uma análise semelhante à que fizemos na Tabela 2, mas com dados da PPV de 1996-1997 para as pessoas com idade entre 21 e 65 anos. De acordo esses dados, menos de $1 \%$ das pessoas cuja mãe tem, no máximo, o ensino fundamental 1 completo fizeram a creche e $19 \%$ fizeram a pré-escola. Já entre os filhos de mãe com ensino superior, cerca de 7,6\% começaram a ir à escola entre $0 \mathrm{e}$ 3 anos de idade e quase $60 \%$ entre 4 e 6 anos de idade. Esse gráfico também destaca a grande influência do nível educacional da mãe na educação do filho. 
FIGURA 2 - PORCENTAGEM DE PESSOAS QUE FIZERAM CRECHE OU PRÉ-ESCOLA POR ESCOLARIDADE DA MÃE

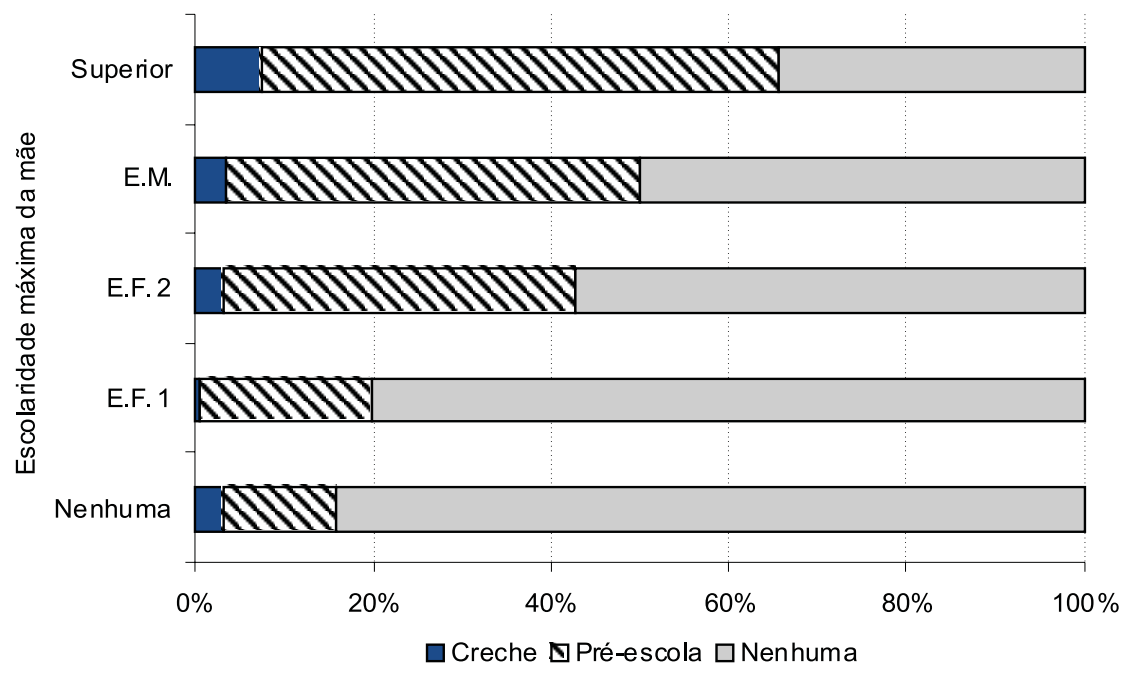

Fonte: PPV, 1996-97. Elaboração própria.

A Tabela 3 mostra as características das pessoas que fizeram creche e/ou pré-escola de acordo com os dados da PPV. As características de sexo e raça não apresentaram influência significativa na determinação da frequência à educação pré-primária. Apenas $1 \%$ das mulheres e $1,14 \%$ dos homens iniciaram a escola entre 0 e 3 anos de idade, e quase $18 \%$ das mulheres e $16,7 \%$ dos homens foram para a escola com idade entre 4 e 6 anos. O relacionamento com a mãe foi mais significativo para influenciar a frequência à pré-escola. A porcentagem de pessoas que foram à pré-escola é maior entre as que viviam com a mãe, o que indica a influência materna na educação do filho. Com relação ao fato de a mãe trabalhar, como esperado, entre os filhos de mães que trabalhavam a porcentagem que fizeram creche e pré-escola é maior. 


\begin{tabular}{|c|c|c|c|}
\hline \multirow[b]{2}{*}{ Características } & & \multicolumn{2}{|c|}{ Início dos estudos } \\
\hline & & Creche & Pré-escola \\
\hline \multirow[t]{2}{*}{ Sexo } & Mulher & $1,00 \%$ & $17,98 \%$ \\
\hline & Homem & $1,14 \%$ & $16,68 \%$ \\
\hline \multirow[t]{2}{*}{ Raça } & Outras & $0,98 \%$ & $17,36 \%$ \\
\hline & Branca & $1,11 \%$ & $17,38 \%$ \\
\hline \multirow[t]{2}{*}{ Vivia com a Mãe } & Não & $0,90 \%$ & $15,26 \%$ \\
\hline & Sim & $1,08 \%$ & $17,62 \%$ \\
\hline \multirow[t]{2}{*}{ Mãe Trabalhava } & Não & $1,02 \%$ & $16,58 \%$ \\
\hline & Sim & $1,16 \%$ & $18,57 \%$ \\
\hline
\end{tabular}

Fonte: PPV, 1996-97. Elaboração própria.

Na Tabela 4 analisamos a relação entre a creche e a pré-escola, e a conclusão dos ciclos escolares e o salário. De acordo com essa tabela, a porcentagem de pessoas entre 21 e 65 anos de idade que completaram os ciclos escolares é maior entre as que iniciaram a escola com idade entre 0 e 6 anos do que entre as pessoas que começaram os estudos depois dos 6 anos de idade. Entre os que frequentaram a creche, quase $94 \%$ completaram o ensino fundamental 1 , e entre os que frequentaram a préescola mais de $95 \%$ completaram esse ciclo, enquanto $76 \%$ dos que não frequentam essas etapas preparatórias têm, pelo menos, quatro anos de estudos. As diferenças ficam mais evidentes para os níveis escolares mais elevados. Os dados mostram que quase $71,3 \%$ dos indivíduos que frequentaram a creche, e $74 \%$ dos indivíduos que frequentaram a pré-escola completaram o ensino fundamental, mas apenas $42 \%$ dos que iniciaram os estudos depois dos 6 anos de idade completaram esse ciclo. Além disso, mais de $50 \%$ dos que frequentaram a creche ou a pré-escola completaram o ensino médio, enquanto apenas $21 \%$ dos que não frequentaram o pré-primário completaram o ensino médio. Com relação à universidade, dos que foram para a escola quando tinham idade entre 0 e 3 anos, 28\% têm nível universitário; entretanto, menos de $5,5 \%$ das pessoas que iniciaram a escola com mais idade têm 15 ou mais anos de estudo completos.

Os dados mostram que, em média, as pessoas que frequentaram a creche têm 11,25 anos de estudo completos e as que iniciaram os estudos na pré-escola completaram 10,6 anos de estudo, enquanto as que foram para a escola depois dos 6 anos de idade completaram, em média, 8,22 anos de estudo, uma diferença de mais de $27 \%$ em relação aos que foram para a creche. Com relação ao salário, a renda das pessoas que 
fizeram creche é, em média, o dobro da renda das pessoas que foram para a escola depois dos 6 anos de idade.

TABELA 4 - RELAÇÃO ENTRE O PRÉ-PRIMÁRIO, A EDUCAÇÃO E O SALÁRIO

\begin{tabular}{llrrr}
\hline & & \multicolumn{3}{c}{ Início dos estudos } \\
\cline { 3 - 5 } & & Creche & Pré-escola & Depois \\
\hline \multirow{2}{*}{ Ensino fundamental 1 } & Não completou & $6,18 \%$ & $4,72 \%$ & $23,73 \%$ \\
& Completou & $93,82 \%$ & $95,28 \%$ & $76,27 \%$ \\
Ensino fundamental 2 & Não completou & $28,77 \%$ & $26,22 \%$ & $64,63 \%$ \\
Ensino médio & Completou & $71,23 \%$ & $73,78 \%$ & $35,37 \%$ \\
Ensino Universitário & Não completou & $49,07 \%$ & $46,63 \%$ & $78,61 \%$ \\
& Completou & $50,93 \%$ & $53,37 \%$ & $21,39 \%$ \\
Anos de estudo & Não completou & $71,81 \%$ & $83,82 \%$ & $94,54 \%$ \\
\multirow{2}{*}{ Renda do Trabalho Principal } & Completou & $28,19 \%$ & $16,18 \%$ & $5,46 \%$ \\
& Média & 11,25 & 10,60 & 8,22 \\
& Desvio padrão & 3,71 & 3,52 & 4,01 \\
\hline
\end{tabular}

Fonte: PPV, 1996-97. Elaboração própria.

Comparando a influência da creche e da pré-escola, notamos, ainda, que as pessoas que começaram os estudos com idade entre 0 e 3 anos têm renda, em média, 9,7\% maior do que as que iniciaram os estudos entre 4 e 6 anos de idade, e 6,15\% mais anos de estudo completos. Além disso, $28,2 \%$ das pessoas que fizeram creche terminaram a universidade, enquanto $16,2 \%$ das que fizeram pré-escola terminaram o ensino superior, uma diferença de $74 \%$.

A Tabela 5 compara o desempenho escolar em matemática dos alunos, medido por exames de proficiência, de acordo com o início dos estudos. A nota média dos alunos da $4^{a}$ série que iniciaram os estudos na pré-escola é quase $19 \%$ maior do que a nota média dos alunos que iniciaram na $1^{\mathrm{a}}, 2^{\mathrm{a}}$, ou $3^{\mathrm{a}}$ série do ensino fundamental. Entre os alunos da $8^{\mathrm{a}}$ séries do ensino fundamental, os que iniciaram os estudos na pré-escola tiveram nota $13,5 \%$ melhor, em média, do que os alunos que começaram a escola na $1^{a}$ série do ensino fundamental ou depois. Entre os alunos da $3^{\text {a }}$ série do ensino médio, a diferença entre a nota média desses dois grupos de alunos é de $14,1 \%$. 
TABELA 5 - RELAÇÃO ENTRE A EDUCAÇÃO PRÉ-PRIMÁRIA E A PROFICIÊNCIA ESCOLAR

\begin{tabular}{llccc}
\hline Início dos estudos & Proficiência & $4^{\text {a }}$ série do E.F. & 8 $^{\text {a }}$ série do E.F. & $3^{\text {a }}$ série do E.M. \\
\hline Pré-escola & Média & 192,35 & 261,62 & 303,86 \\
& Desvio padrão & 47,03 & 55,36 & 65,06 \\
& Média & 162,12 & 230,48 & 266,29 \\
$1^{\mathrm{a}}, 2^{\mathrm{a}}$ ou 3 & a & 36,65 & 46,50 & 55,69 \\
série do E.F. & Desvio padrão & \\
\hline
\end{tabular}

Fonte: SAEB, 2003 Elaboração própria.

\section{RESULTADOS ECONOMÉTRICOS}

\subsection{Relação entre a Educação Pré-Primária e a Conclusão dos Ciclos Escolares}

A Tabela 6 mostra os resultados da estimação do modelo Logit em que a variável dependente é uma variável binária que indica se o indivíduo tem, ou não, pelo menos, quatro anos de estudo completos. Os resultados indicam que as pessoas que fizeram pré-escola - iniciaram os estudos entre 4 e 6 anos de idade - têm maior probabilidade de concluir o ensino fundamental 1 do que as demais. Entretanto, ter iniciado os estudos entre 0 e 3 anos de idade tem efeito negativo na conclusão desse ciclo quando incluímos as variáveis de educação dos pais, mas esse efeito não é estatisticamente significante. Controlando por todas as variáveis (coluna IV), o efeito marginal da pré-escola na conclusão do ensino fundamental 1 é de $4 \%$. 
TABELA 6 - EFEITOS MARGINAIS NA CONCLUSÃO DO ENSINO FUNDAMENTAL 1

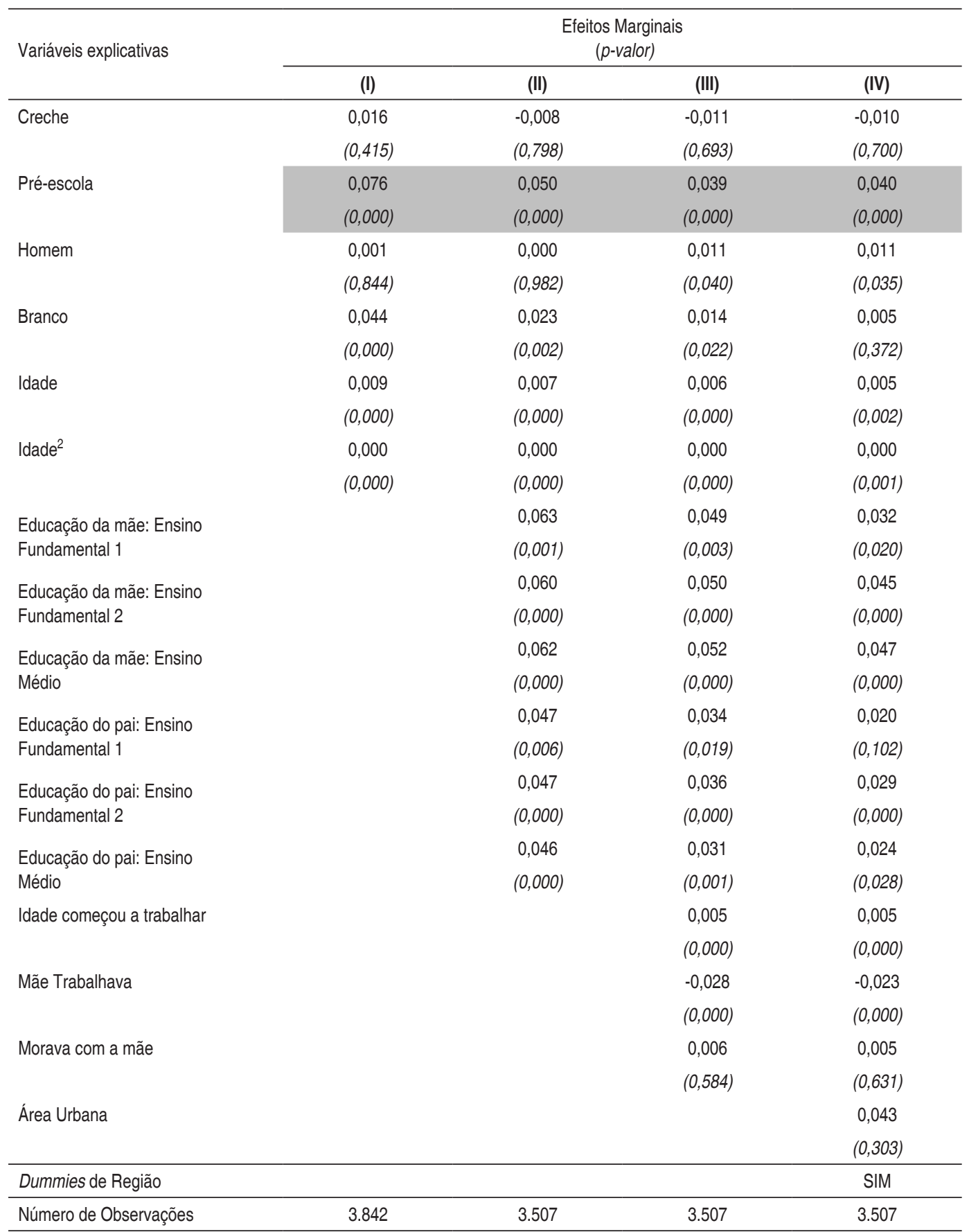




\section{TABELA 7 - EFEITOS MARGINAIS NA CONCLUSÃO DO ENSINO FUNDA- MENTAL 2}

\begin{tabular}{|c|c|c|c|c|}
\hline \multirow[t]{2}{*}{ Variáveis explicativas } & \multicolumn{4}{|c|}{$\begin{array}{l}\text { Efeitos Marginais } \\
\text { (p-valor) }\end{array}$} \\
\hline & (l) & (III) & (III) & (IV) \\
\hline \multirow[t]{2}{*}{ Creche } & 0,175 & 0,046 & 0,051 & 0,027 \\
\hline & $(0,000)$ & $(0,482)$ & $(0,417)$ & $(0,686)$ \\
\hline \multirow[t]{2}{*}{ Pré-escola } & 0,280 & 0,204 & 0,189 & 0,179 \\
\hline & $(0,000)$ & $(0,000)$ & $(0,000)$ & $(0,000)$ \\
\hline \multirow[t]{2}{*}{ Homem } & $-0,020$ & $-0,031$ & 0,014 & 0,014 \\
\hline & $(0,193)$ & $(0,038)$ & $(0,370)$ & $(0,373)$ \\
\hline \multirow[t]{2}{*}{ Branco } & 0,132 & 0,075 & 0,064 & 0,074 \\
\hline & $(0,000)$ & $(0,000)$ & $(0,000)$ & $(0,000)$ \\
\hline \multirow[t]{2}{*}{ Idade } & 0,020 & 0,018 & 0,018 & 0,017 \\
\hline & $(0,000)$ & $(0,000)$ & $(0,000)$ & $(0,001)$ \\
\hline \multirow[t]{2}{*}{ Idade $^{2}$} & 0,000 & 0,000 & 0,000 & 0,000 \\
\hline & $(0,000)$ & $(0,000)$ & $(0,000)$ & $(0,001)$ \\
\hline \multirow{2}{*}{ Educação da mãe: Ensino Fundamental 1} & & 0,159 & 0,145 & 0,143 \\
\hline & & $(0,001)$ & $(0,002)$ & $(0,003)$ \\
\hline \multirow{2}{*}{ Educação da mãe: Ensino Fundamental 2} & & 0,183 & 0,168 & 0,166 \\
\hline & & $(0,000)$ & $(0,000)$ & $(0,000)$ \\
\hline \multirow{2}{*}{ Educação da mãe: Ensino Médio } & & 0,293 & 0,285 & 0,285 \\
\hline & & $(0,000)$ & $(0,000)$ & $(0,000)$ \\
\hline \multirow{2}{*}{ Educação da mãe: Ensino Superior } & & 0,287 & 0,280 & 0,280 \\
\hline & & $(0,000)$ & $(0,000)$ & $(0,000)$ \\
\hline \multirow{2}{*}{ Educação do pai: Ensino Fundamental 1} & & 0,190 & 0,186 & 0,173 \\
\hline & & $(0,000)$ & $(0,000)$ & $(0,001)$ \\
\hline \multirow{2}{*}{ Educação do pai: Ensino Fundamental 2} & & 0,200 & 0,186 & 0,179 \\
\hline & & $(0,000)$ & $(0,000)$ & $(0,000)$ \\
\hline \multirow{2}{*}{ Educação do pai: Ensino Médio } & & 0,285 & 0,262 & 0,259 \\
\hline & & $(0,000)$ & $(0,000)$ & $(0,000)$ \\
\hline \multirow{2}{*}{ Educação do pai: Ensino Superior } & & 0,300 & 0,279 & 0,275 \\
\hline & & $(0,000)$ & $(0,000)$ & $(0,000)$ \\
\hline \multirow[t]{2}{*}{ Idade começou a trabalhar } & & & 0,020 & 0,019 \\
\hline & & & $(0,000)$ & $(0,000)$ \\
\hline \multirow[t]{2}{*}{ Mãe Trabalhava } & & & $-0,064$ & $-0,067$ \\
\hline & & & $(0,000)$ & $(0,000)$ \\
\hline \multirow[t]{2}{*}{ Morava com a mãe } & & & 0,082 & 0,082 \\
\hline & & & $(0,015)$ & $(0,017)$ \\
\hline \multirow[t]{2}{*}{ Área Urbana } & & & & 0,075 \\
\hline & & & & $(0,473)$ \\
\hline Dummies de Região & & & & SIM \\
\hline Número de Observações & 3.842 & 3.820 & 3.820 & 3.820 \\
\hline
\end{tabular}


Ainda de acordo com essa estimação, os homens têm maior probabilidade de conclusão do ensino fundamental 1 do que as mulheres, e a raça só é significante nas estimaçôes em que o local de moradia não foi considerado. A idade é positivamente relacionada à conclusão desse ciclo, assim como a educação dos pais e a idade em que a pessoa começou a trabalhar. Isto é, quanto maior o nível educacional dos pais, maior a probabilidade de conclusão do ensino fundamental 1 , e quanto mais tarde começou a trabalhar, maior a probabilidade de conclusão desse ciclo. $\mathrm{O}$ fato de a mãe trabalhar quando a pessoa tinha 15 anos de idade mostrou-se negativamente relacionado a concluir os quatro primeiros anos de estudo.

A Tabela 7 mostra os resultados da estimação do modelo Logit em que a variável dependente indica se o indivíduo tem, ou não, pelo menos, 8 anos de estudo completos. Os resultados indicam que tanto a pré-escola quanto a creche têm relação positiva com a conclusão do ensino fundamental 2. Porém, ao contrário da pré-escola, ter frequentado a creche não é estatisticamente significante quando controlamos o modelo pela educação dos pais. O efeito marginal da pré-escola sobre a conclusão do ensino fundamental 2 é maior do que sobre a conclusão do ensino fundamental 1 , em torno de $18 \%$.

Em relação às demais variáveis do modelo, as estimações mostram que os brancos apresentam maior probabilidade de concluir esse ciclo escolar do que as pessoas de outras raças. A idade da pessoa, a educação dos pais, a idade em que começou a trabalhar e ter vivido com a mãe aos 15 anos de idade são positivamente correlacionadas com a conclusão de, pelo menos, oito anos de estudo. $\mathrm{O}$ fato de a mãe trabalhar reduz a probabilidade de terminar o ensino fundamental 2.

A Tabela 8 mostra os resultados da estimação do modelo Logit em que a variável dependente é uma variável binária que indica se o indivíduo tem, ou não, pelo menos 11 anos de estudo completos. Os resultados indicam que as pessoas que fizeram creche e/ou pré-escola têm maior probabilidade de concluir o ensino fundamental 2 do que as que iniciaram os estudos a partir dos 7 anos de idade. Os efeitos de ambas as variáveis são positivos e significantes. Os resultados mostram, ainda, que a influência da pré-escola é maior do que a influência da creche na conclusão do ensino médio. O efeito marginal de ter frequentado a escola entre 4 e 6 anos de idade é de $24 \%$, e de ter iniciado os estudos entre 0 e 3 anos de idade é de $13 \%$. 


\section{TABELA 8 - EFEITOS MARGINAIS NA CONCLUSÃO DO ENSINO MÉDIO}

\begin{tabular}{|c|c|c|c|c|}
\hline \multirow[t]{2}{*}{ Variáveis explicativas } & \multicolumn{4}{|c|}{$\begin{array}{l}\text { Efeitos Marginais } \\
\quad(p \text {-valor })\end{array}$} \\
\hline & (l) & (II) & (III) & (IV) \\
\hline \multirow[t]{2}{*}{ Creche } & 0,305 & 0,134 & 0,142 & 0,129 \\
\hline & $(0,000)$ & $(0,080)$ & $(0,067)$ & $(0,100)$ \\
\hline \multirow[t]{2}{*}{ Pré-escola } & 0,334 & 0,260 & 0,247 & 0,238 \\
\hline & $(0,000)$ & $(0,000)$ & $(0,000)$ & $(0,000)$ \\
\hline \multirow[t]{2}{*}{ Homem } & $-0,034$ & $-0,050$ & $-0,001$ & 0,000 \\
\hline & $(0,046)$ & $(0,006)$ & $(0,951)$ & $(0,986)$ \\
\hline \multirow[t]{2}{*}{ Branco } & 0,186 & 0,138 & 0,128 & 0,141 \\
\hline & $(0,000)$ & $(0,000)$ & $(0,000)$ & $(0,000)$ \\
\hline \multirow[t]{2}{*}{ Idade } & 0,040 & 0,044 & 0,044 & 0,044 \\
\hline & $(0,000)$ & $(0,000)$ & $(0,000)$ & $(0,000)$ \\
\hline \multirow[t]{2}{*}{ Idade $^{2}$} & 0,000 & 0,000 & $-0,001$ & $-0,001$ \\
\hline & $(0,000)$ & $(0,000)$ & $(0,000)$ & $(0,000)$ \\
\hline \multirow{2}{*}{ Educação da mãe: Ensino Fundamental 1} & & 0,139 & 0,126 & 0,126 \\
\hline & & $(0,017)$ & $(0,036)$ & $(0,039)$ \\
\hline \multirow{2}{*}{ Educação da mãe: Ensino Fundamental 2} & & 0,235 & 0,219 & 0,222 \\
\hline & & $(0,000)$ & $(0,000)$ & $(0,000)$ \\
\hline \multirow{2}{*}{ Educação da mãe: Ensino Médio } & & 0,383 & 0,381 & 0,381 \\
\hline & & $(0,000)$ & $(0,000)$ & $(0,000)$ \\
\hline \multirow{2}{*}{ Educação da mãe: Ensino Superior } & & 0,427 & 0,432 & 0,427 \\
\hline & & $(0,000)$ & $(0,000)$ & $(0,000)$ \\
\hline \multirow{2}{*}{ Educação do pai: Ensino Fundamental 1} & & 0,206 & 0,205 & 0,203 \\
\hline & & $(0,001)$ & $(0,001)$ & $(0,001)$ \\
\hline \multirow{2}{*}{ Educação do pai: Ensino Fundamental 2} & & 0,278 & 0,266 & 0,274 \\
\hline & & $(0,000)$ & $(0,000)$ & $(0,000)$ \\
\hline \multirow{2}{*}{ Educação do pai: Ensino Médio } & & 0,435 & 0,404 & 0,409 \\
\hline & & $(0,000)$ & $(0,000)$ & $(0,000)$ \\
\hline \multirow{2}{*}{ Educação do pai: Ensino Superior } & & 0,461 & 0,431 & 0,433 \\
\hline & & $(0,000)$ & $(0,000)$ & $(0,000)$ \\
\hline \multirow[t]{2}{*}{ Idade começou a trabalhar } & & & 0,022 & 0,022 \\
\hline & & & $(0,000)$ & $(0,000)$ \\
\hline \multirow[t]{2}{*}{ Mãe Trabalhava } & & & $-0,090$ & $-0,096$ \\
\hline & & & $(0,000)$ & $(0,000)$ \\
\hline \multirow[t]{2}{*}{ Morava com a mãe } & & & 0,098 & 0,095 \\
\hline & & & $(0,008)$ & $(0,012)$ \\
\hline \multirow[t]{2}{*}{ Área Urbana } & & & & 0,067 \\
\hline & & & & $(0,600)$ \\
\hline Dummies de Região & & & & SIM \\
\hline Número de Observações & 3.842 & 3.835 & 3.835 & 3.835 \\
\hline
\end{tabular}


A Tabela 9 mostra os resultados da estimação do modelo Logit em que a variável dependente indica se o indivíduo concluiu, ou não, pelo menos, 15 anos de estudo. Os resultados indicam que as pessoas que fizeram creche e/ou pré-escola têm maior probabilidade de completar os estudos universitários do que as pessoas que iniciaram os estudos a partir dos 7 anos de idade. Ao contrário do ensino médio, a influência da creche na conclusão da universidade é maior do que a influência da pré-escola. De acordo com a estimação apresentada na coluna (IV), o efeito marginal da creche na conclusão da universidade é de $19 \%$, enquanto o efeito marginal da pré-escola é de $5,5 \%$.

Com relação às demais variáveis, as Tabelas 7 e 8 mostram que os brancos apresentam maior probabilidade de concluir o ensino médio e universitário do que as pessoas de outra raça. A idade da pessoa, a educação dos pais, a idade em que começou a trabalhar e ter vivido com a mãe aos 15 anos de idade são positivamente relacionadas à conclusão desses ciclos escolares. $\mathrm{O}$ fato de a mãe trabalhar reduz a probabilidade de terminar o ensino médio, mas não está significantemente relacionado à conclusão da universidade. 
TABELA 9 - EFEITOS MARGINAIS NA CONCLUSÃO DA UNIVERSIDADE

\begin{tabular}{|c|c|c|c|c|}
\hline \multirow[t]{2}{*}{ Variáveis explicativas } & \multicolumn{4}{|c|}{$\begin{array}{c}\text { Efeitos Marginais } \\
(p \text {-valor })\end{array}$} \\
\hline & $(\mathrm{l})$ & (III) & (III) & (IV) \\
\hline \multirow[t]{2}{*}{ Creche } & 0,456 & 0,187 & 0,179 & 0,190 \\
\hline & $(0,000)$ & $(0,004)$ & $(0,005)$ & $(0,004)$ \\
\hline \multirow[t]{2}{*}{ Pré-escola } & 0,169 & 0,067 & 0,059 & 0,055 \\
\hline & $(0,000)$ & $(0,000)$ & $(0,000)$ & $(0,000)$ \\
\hline \multirow[t]{2}{*}{ Homem } & $-0,002$ & $-0,005$ & 0,013 & 0,012 \\
\hline & $(0,845)$ & $(0,600)$ & $(0,146)$ & $(0,114)$ \\
\hline \multirow[t]{2}{*}{ Branco } & 0,099 & 0,060 & 0,054 & 0,041 \\
\hline & $(0,000)$ & $(0,000)$ & $(0,000)$ & $(0,000)$ \\
\hline \multirow[t]{2}{*}{ Idade } & 0,031 & 0,029 & 0,028 & 0,024 \\
\hline & $(0,000)$ & $(0,000)$ & $(0,000)$ & $(0,000)$ \\
\hline \multirow[t]{2}{*}{ Idade $^{2}$} & 0,000 & 0,000 & 0,000 & 0,000 \\
\hline & $(0,000)$ & $(0,000)$ & $(0,000)$ & $(0,000)$ \\
\hline \multirow{2}{*}{ Educação da mãe: Ensino Fundamental 1} & & 0,045 & 0,038 & 0,023 \\
\hline & & $(0,242)$ & $(0,312)$ & $(0,484)$ \\
\hline \multirow{2}{*}{ Educação da mãe: Ensino Fundamental 2} & & 0,150 & 0,128 & 0,098 \\
\hline & & $(0,102)$ & $(0,136)$ & $(0,174)$ \\
\hline \multirow{2}{*}{ Educação da mãe: Ensino Médio } & & 0,161 & 0,125 & 0,091 \\
\hline & & $(0,095)$ & $(0,150)$ & $(0,204)$ \\
\hline \multirow{2}{*}{ Educação da mãe: Ensino Superior } & & 0,278 & 0,234 & 0,172 \\
\hline & & $(0,038)$ & $(0,067)$ & $(0,112)$ \\
\hline \multirow{2}{*}{ Educação do pai: Ensino Fundamental 1} & & 0,110 & 0,108 & 0,088 \\
\hline & & $(0,030)$ & $(0,027)$ & $(0,038)$ \\
\hline \multirow{2}{*}{ Educação do pai: Ensino Fundamental 2} & & 0,366 & 0,356 & 0,305 \\
\hline & & $(0,060)$ & $(0,069)$ & $(0,098)$ \\
\hline \multirow{2}{*}{ Educação do pai: Ensino Médio } & & 0,536 & 0,501 & 0,452 \\
\hline & & $(0,005)$ & $(0,012)$ & $(0,026)$ \\
\hline \multirow{2}{*}{ Educação do pai: Ensino Superior } & & 0,671 & 0,641 & 0,594 \\
\hline & & $(0,000)$ & $(0,000)$ & $(0,002)$ \\
\hline \multirow[t]{2}{*}{ Idade começou a trabalhar } & & & 0,006 & 0,006 \\
\hline & & & $(0,000)$ & $(0,000)$ \\
\hline \multirow[t]{2}{*}{ Mãe Trabalhava } & & & 0,003 & 0,003 \\
\hline & & & $(0,721)$ & $(0,728)$ \\
\hline \multirow[t]{2}{*}{ Morava com a mãe } & & & 0,035 & 0,028 \\
\hline & & & $(0,015)$ & $(0,025)$ \\
\hline \multirow[t]{2}{*}{ Área Urbana } & & & & 0,230 \\
\hline & & & & $(0,000)$ \\
\hline Dummies de Região & & & & SIM \\
\hline Número de Observações & 3.842 & 3.842 & 3.842 & 3.842 \\
\hline
\end{tabular}




\section{FIGURA 3 - EFEITOS MARGINAIS DA EDUCAÇÃO PRÉ-PRIMÁRIA NOS CICLOS ESCOLARES}

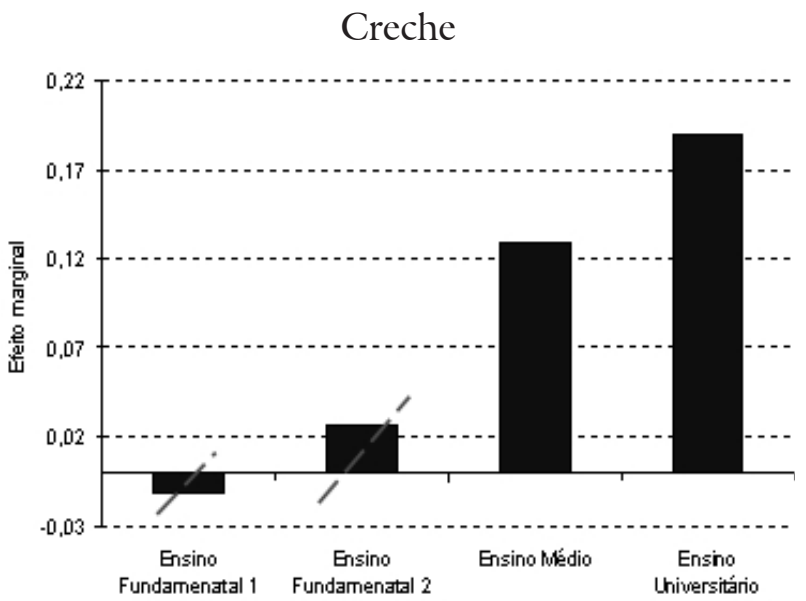

Nota: ', não é estatisticamente significante a $10 \%$.

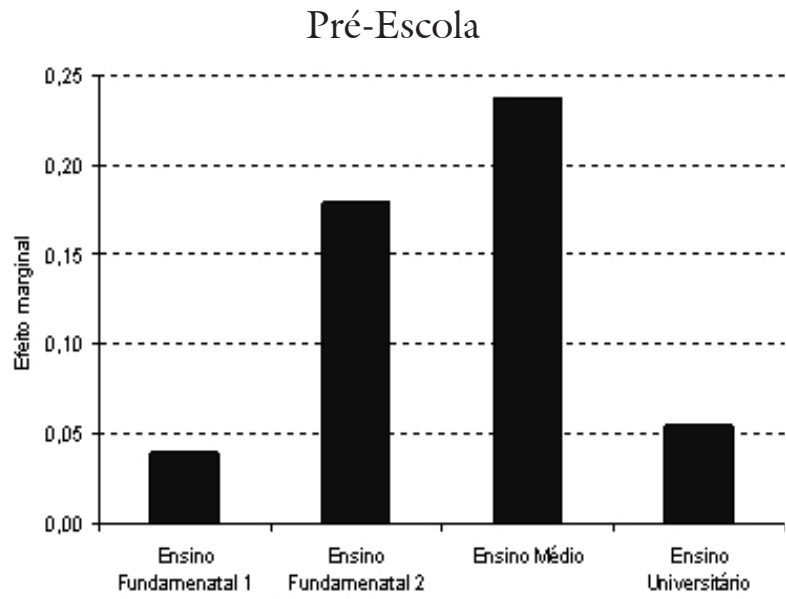

Sintetizando, a Figura 3 destaca os efeitos marginais estimados pelo modelo Logit da Creche e da Pré-escola sobre a conclusão dos ciclos escolares (resultados das colunas IV da Tabela 6, Tabela 7, Tabela 8 e Tabela 9). Os resultados mostram que a préescola tem relação positiva e significante com a conclusão dos quatro ciclos escolares, com efeito marginal crescente nos três primeiros, e que a creche tem relação positiva e significante apenas com a conclusão do ensino médio e do ensino universitário. Frequentar a pré-escolar aumenta a probabilidade de concluir o ensino fundamental 1 , o ensino fundamental 2 , o ensino médio e o ensino universitário em $4 \%, 18 \%$, $24 \%$ e $5,5 \%$, respectivamente, mesmo quando controlamos pela educação dos pais. Frequentar a creche, por sua vez, tem relação positiva e significante de $13 \%$ com a conclusão do ensino médio, e de $19 \%$ com a conclusão do ensino universitário 
utilizando os mesmos controles. Comparando os efeitos marginais de frequentar a creche e a pré-escola, notamos que o efeito marginal da creche sobre a conclusão da universidade é mais de três vezes maior do que o efeito marginal da pré-escola sobre o ensino universitário. Por outro lado, o efeito marginal da pré-escola sobre a conclusão do ensino médio é quase o dobro do efeito da creche sobre a conclusão desse ciclo. O impacto crescente da creche e côncavo da pré-escola ao longo dos ciclos merece uma reflexão mais aprofundada. Isto pode significar que os efeitos da pré-escola são mais imediatos, porém de curto prazo, enquanto os efeitos adicionais da creche demoram mais para aparecer, mas duram mais tempo. Seria necessário um estudo mais aprofundado sobre este tema, com referências na área de desenvolvimento cognitivo, o que fugiria aos objetivos deste trabalho.

A Tabela 10 apresenta o resultado da estimação por Mínimos Quadrados em que a variável dependente é a quantidade de anos de estudos completos. As pessoas que iniciaram os estudos entre 0 e 3 anos de idade ou entre 4 e 6 anos de idade têm, em média, mais anos de estudos completos do que as pessoas que começaram a frequentar a escola a partir dos 7 anos de idade. A influência da pré-escola é maior do que a influência da creche na conclusão dos anos de estudo.

\subsection{Relação entre a Educação Pré-Primária e o Salário}

A Tabela 11 mostra os resultados da estimação do modelo em que a variável dependente é a renda do trabalho principal em logaritmo.

De acordo com a estimação, ter iniciado os estudos entre 0 e 6 anos de idade tem efeitos positivos no salário. Entretanto, frequentar a creche não é estatisticamente significante na presença das variáveis de educação dos pais. Ao contrário, o efeito da pré-escola é significante no salário.

As estimações mostram que a pré-escola tem relação positiva com a renda dos indivíduos, independentemente do seu impacto na educação. A pré-escola apresenta uma elasticidade em torno de 0,16 quando controlamos pela educação do indivíduo (colunas I a IV). Na ausência da variável de educação, a elasticidade é maior, chegando a 0,27 (coluna V).

Com relação às demais variáveis do modelo, elas indicam que os homens, em média, ganham mais do que as mulheres, e que a idade e o nível educacional do indivíduo são positivamente relacionados à renda do trabalho principal. Além disso, a educação do pai tem uma relação positiva e significante com o salário do filho, mas educação da mãe não é estatisticamente significante. 


\section{TABELA 10 - EFEITOS DA EDUCAÇÃO PRÉ-PRIMÁRIA NA CONCLUSÃO DOS ANOS DE ESTUDOS}

\begin{tabular}{|c|c|c|c|c|}
\hline \multirow[t]{2}{*}{ Variáveis explicativas } & \multicolumn{4}{|c|}{$\begin{array}{c}\text { Coeficiente } \\
\text { (p-valor) }\end{array}$} \\
\hline & (l) & (II) & (III) & (IV) \\
\hline \multirow[t]{2}{*}{ Creche } & 3,045 & 1,224 & 1,178 & 1,106 \\
\hline & $(0,000)$ & $(0,006)$ & $(0,006)$ & $(0,009)$ \\
\hline \multirow[t]{2}{*}{ Pré-escola } & 2,896 & 1,794 & 1,614 & 1,575 \\
\hline & $(0,000)$ & $(0,000)$ & $(0,000)$ & $(0,000)$ \\
\hline \multirow[t]{2}{*}{ Homem } & $-0,092$ & $-0,170$ & 0,234 & 0,238 \\
\hline & $(0,453)$ & $(0,126)$ & $(0,037)$ & $(0,032)$ \\
\hline \multirow[t]{2}{*}{ Branco } & 1,545 & 0,938 & 0,813 & 0,765 \\
\hline & $(0,000)$ & $(0,000)$ & $(0,000)$ & $(0,000)$ \\
\hline \multirow[t]{2}{*}{ Idade } & 0,321 & 0,295 & 0,288 & 0,275 \\
\hline & $(0,000)$ & $(0,000)$ & $(0,000)$ & $(0,000)$ \\
\hline \multirow[t]{2}{*}{ Idade $^{2}$} & $-0,004$ & $-0,003$ & $-0,003$ & $-0,003$ \\
\hline & $(0,000)$ & $(0,000)$ & $(0,000)$ & $(0,000)$ \\
\hline \multirow[t]{2}{*}{ Educação da mãe: Ensino Fundamental 1} & & 1,516 & 1,331 & 1,176 \\
\hline & & $(0,000)$ & $(0,000)$ & $(0,000)$ \\
\hline \multirow[t]{2}{*}{ Educação da mãe: Ensino Fundamental 2} & & 2,492 & 2,218 & 2,079 \\
\hline & & $(0,000)$ & $(0,000)$ & $(0,000)$ \\
\hline \multirow[t]{2}{*}{ Educação da mãe: Ensino Médio } & & 3,430 & 3,150 & 2,975 \\
\hline & & $(0,000)$ & $(0,000)$ & $(0,000)$ \\
\hline \multirow[t]{2}{*}{ Educação da mãe: Ensino Superior } & & 3,797 & 3,662 & 3,408 \\
\hline & & $(0,000)$ & $(0,000)$ & $(0,000)$ \\
\hline \multirow[t]{2}{*}{ Educação do pai: Ensino Fundamental 1} & & 1,978 & 1,846 & 1,654 \\
\hline & & $(0,000)$ & $(0,000)$ & $(0,000)$ \\
\hline \multirow[t]{2}{*}{ Educação do pai: Ensino Fundamental 2} & & 2,955 & 2,684 & 2,490 \\
\hline & & $(0,000)$ & $(0,000)$ & $(0,000)$ \\
\hline \multirow[t]{2}{*}{ Educação do pai: Ensino Médio } & & 4,489 & 3,854 & 3,673 \\
\hline & & $(0,000)$ & $(0,000)$ & $(0,000)$ \\
\hline \multirow[t]{2}{*}{ Educação do pai: Ensino Superior } & & 5,037 & 4,299 & 4,122 \\
\hline & & $(0,000)$ & $(0,000)$ & $(0,000)$ \\
\hline \multirow[t]{2}{*}{ Idade começou a trabalhar } & & & 0,173 & 0,171 \\
\hline & & & $(0,000)$ & $(0,000)$ \\
\hline \multirow[t]{2}{*}{ Mãe Trabalhava } & & & $-0,447$ & $-0,454$ \\
\hline & & & $(0,000)$ & $(0,000)$ \\
\hline \multirow[t]{2}{*}{ Morava com a mãe } & & & 0,626 & 0,565 \\
\hline & & & $(0,004)$ & $(0,009)$ \\
\hline \multirow[t]{2}{*}{ Urbana } & & & & 0,882 \\
\hline & & & & $(0,196)$ \\
\hline Dummies de Região & & & & SIM \\
\hline \multirow[t]{2}{*}{ Constante } & 0,892 & $-2,129$ & $-4,603$ & $-4,756$ \\
\hline & $(0,255)$ & $(0,005)$ & $(0,000)$ & $(0,000)$ \\
\hline Número de Observações & 3.842 & 3.842 & 3.842 & 3.842 \\
\hline$R^{2}$ & 0,131 & 0,290 & 0,335 & 0,351 \\
\hline
\end{tabular}




\section{TABELA 11 - EFEITOS DA EDUCAÇÃO PRÉ-PRIMÁRIA NO SALÁRIO}

\begin{tabular}{|c|c|c|c|c|c|}
\hline \multirow[t]{2}{*}{ Variáveis explicativas } & \multicolumn{5}{|c|}{ Coeficiente ( $p$-valor) } \\
\hline & (l) & (II) & (III) & (IV) & $(\mathrm{V})$ \\
\hline Creche & $\begin{array}{c}0,234 \\
(0,102)\end{array}$ & $\begin{array}{c}0,148 \\
(0,299)\end{array}$ & $\begin{array}{c}0,149 \\
(0,298)\end{array}$ & $\begin{array}{c}0,151 \\
(0,273)\end{array}$ & $\begin{array}{c}0,152 \\
(0,311)\end{array}$ \\
\hline Pré-escola & $\begin{array}{c}0,165 \\
(0,000)\end{array}$ & $\begin{array}{c}0,118 \\
(0,012)\end{array}$ & $\begin{array}{c}0,119 \\
(0,011)\end{array}$ & $\begin{array}{c}0,164 \\
(0,000)\end{array}$ & $\begin{array}{c}0,272 \\
(0,000)\end{array}$ \\
\hline Homem & $\begin{array}{c}0,721 \\
(0,000)\end{array}$ & $\begin{array}{c}0,716 \\
(0,000)\end{array}$ & $\begin{array}{c}0,701 \\
(0,000)\end{array}$ & $\begin{array}{c}0,677 \\
(0,000)\end{array}$ & $\begin{array}{c}0,643 \\
(0,000)\end{array}$ \\
\hline Branco & $\begin{array}{c}0,113 \\
(0,008)\end{array}$ & $\begin{array}{c}0,099 \\
(0,019)\end{array}$ & $\begin{array}{c}0,096 \\
(0,024)\end{array}$ & $\begin{array}{l}-0,068 \\
(0,131)\end{array}$ & $\begin{array}{c}0,014 \\
(0,774)\end{array}$ \\
\hline Idade & $\begin{array}{c}0,134 \\
(0,000)\end{array}$ & $\begin{array}{l}0,141 \\
(0,000)\end{array}$ & $\begin{array}{c}0,141 \\
(0,000)\end{array}$ & $\begin{array}{c}0,134 \\
(0,000)\end{array}$ & $\begin{array}{c}0,161 \\
(0,000)\end{array}$ \\
\hline Idade $^{2}$ & $\begin{array}{l}-0,001 \\
(0,000)\end{array}$ & $\begin{array}{l}-0,001 \\
(0,000)\end{array}$ & $\begin{array}{l}-0,001 \\
(0,000)\end{array}$ & $\begin{array}{l}-0,001 \\
(0,000)\end{array}$ & $\begin{array}{l}-0,002 \\
(0,000)\end{array}$ \\
\hline Educação: Ensino Fundamental 1 & $\begin{array}{c}0,102 \\
(0,801)\end{array}$ & $\begin{array}{c}0,011 \\
(0,979)\end{array}$ & $\begin{array}{l}-0,002 \\
(0,996)\end{array}$ & $\begin{array}{l}-0,193 \\
(0,618)\end{array}$ & \\
\hline Educação: Ensino Fundamental 2 & $\begin{array}{c}0,535 \\
(0,185)\end{array}$ & $\begin{array}{c}0,412 \\
(0,309)\end{array}$ & $\begin{array}{c}0,405 \\
(0,317)\end{array}$ & $\begin{array}{c}0,071 \\
(0,855)\end{array}$ & \\
\hline Educação: Ensino Médio & $\begin{array}{c}0,918 \\
(0,023)\end{array}$ & $\begin{array}{c}0,749 \\
(0,064)\end{array}$ & $\begin{array}{c}0,749 \\
(0,064)\end{array}$ & $\begin{array}{c}0,455 \\
(0,239)\end{array}$ & \\
\hline Educação: Ensino Superior & $\begin{array}{c}1,603 \\
(0,000)\end{array}$ & $\begin{array}{c}1,349 \\
(0,001)\end{array}$ & $\begin{array}{c}1,360 \\
(0,001)\end{array}$ & $\begin{array}{l}1,012 \\
(0,009)\end{array}$ & \\
\hline Educação: Mestrado ou Doutorado & $\begin{array}{c}2,105 \\
(0,000)\end{array}$ & $\begin{array}{l}1,754 \\
(0,000)\end{array}$ & $\begin{array}{c}1,762 \\
(0,000)\end{array}$ & $\begin{array}{c}1,456 \\
(0,000)\end{array}$ & \\
\hline Educação da mãe: Ensino Fundamental 1 & & $\begin{array}{c}0,054 \\
(0,659)\end{array}$ & $\begin{array}{c}0,061 \\
(0,618)\end{array}$ & $\begin{array}{l}-0,022 \\
(0,852)\end{array}$ & $\begin{array}{c}0,029 \\
(0,823)\end{array}$ \\
\hline Educação da mãe: Ensino Fundamental 2 & & $\begin{array}{c}0,067 \\
(0,616)\end{array}$ & $\begin{array}{c}0,081 \\
(0,544)\end{array}$ & $\begin{array}{l}-0,005 \\
(0,967)\end{array}$ & $\begin{array}{c}0,088 \\
(0,525)\end{array}$ \\
\hline Educação da mãe: Ensino Médio & & $\begin{array}{l}-0,036 \\
(0,790)\end{array}$ & $\begin{array}{l}-0,022 \\
(0,872)\end{array}$ & $\begin{array}{l}-0,106 \\
(0,422)\end{array}$ & $\begin{array}{c}0,064 \\
(0,655)\end{array}$ \\
\hline Educação da mãe: Ensino Superior & & $\begin{array}{c}0,055 \\
(0,734)\end{array}$ & $\begin{array}{c}0,070 \\
(0,671)\end{array}$ & $\begin{array}{l}-0,029 \\
(0,855)\end{array}$ & $\begin{array}{c}0,180 \\
(0,294)\end{array}$ \\
\hline Educação do pai: Ensino Fundamental 1 & & $\begin{array}{c}0,189 \\
(0,207)\end{array}$ & $\begin{array}{c}0,179 \\
(0,234)\end{array}$ & $\begin{array}{c}0,125 \\
(0,386)\end{array}$ & $\begin{array}{c}0,334 \\
(0,033)\end{array}$ \\
\hline Educação do pai: Ensino Fundamental 2 & & $\begin{array}{c}0,354 \\
(0,027)\end{array}$ & $\begin{array}{c}0,346 \\
(0,032)\end{array}$ & $\begin{array}{c}0,266 \\
(0,085)\end{array}$ & $\begin{array}{c}0,611 \\
(0,000)\end{array}$ \\
\hline Educação do pai: Ensino Médio & & $\begin{array}{c}0,526 \\
(0,001)\end{array}$ & $\begin{array}{c}0,523 \\
(0,002)\end{array}$ & $\begin{array}{c}0,480 \\
(0,003)\end{array}$ & $\begin{array}{c}0,929 \\
(0,000)\end{array}$ \\
\hline Educação do pai: Ensino Superior & & $\begin{array}{c}0,624 \\
(0,000)\end{array}$ & $\begin{array}{c}0,624 \\
(0,000)\end{array}$ & $\begin{array}{c}0,512 \\
(0,002)\end{array}$ & $\begin{array}{c}1,066 \\
(0,000)\end{array}$ \\
\hline Idade começou a trabalhar & & & $\begin{array}{l}-0,006 \\
(0,179)\end{array}$ & $\begin{array}{l}0,000 \\
(0,984)\end{array}$ & $\begin{array}{c}0,019 \\
(0,000)\end{array}$ \\
\hline Mãe Trabalhava & & & $\begin{array}{l}-0,020 \\
(0,644)\end{array}$ & $\begin{array}{c}0,005 \\
(0,907)\end{array}$ & $\begin{array}{c}-0,012 \\
(0,790)\end{array}$ \\
\hline Morava com a mãe & & & $\begin{array}{l}-0,046 \\
(0,578)\end{array}$ & $\begin{array}{l}-0,080 \\
(0,315)\end{array}$ & $\begin{array}{c}0,012 \\
(0,893)\end{array}$ \\
\hline Urbana & & & & $\begin{array}{c}0,280 \\
(0,217)\end{array}$ & $\begin{array}{c}0,345 \\
(0,163)\end{array}$ \\
\hline Dummies de Região & & & & SIM & SIM \\
\hline Constante & $\begin{array}{c}2,063 \\
(0,000)\end{array}$ & $\begin{array}{c}1,816 \\
(0,000)\end{array}$ & $\begin{array}{c}1,983 \\
(0,000)\end{array}$ & $\begin{array}{l}2,211 \\
(0,000)\end{array}$ & $\begin{array}{c}1,286 \\
(0,002) \\
\end{array}$ \\
\hline Número de Observações & 1.836 & 1.836 & 1.836 & 1.836 & 1.836 \\
\hline$R^{2}$ & 0,412 & 0,427 & 0,428 & 0,483 & 0,381 \\
\hline
\end{tabular}




\subsection{Relação entre a Educação Pré-Primária e o Desempenho Escolar (Proficiência) ${ }^{3}$}

Nessa seção analisamos os efeitos de frequentar a pré-escola no desempenho escolar dos alunos, medido por exames de proficiência em matemática realizados em 2003 pelo SAEB para os alunos da $4^{\mathrm{a}}$ e da $8^{\mathrm{a}}$ séries do ensino fundamental e da $3^{\mathrm{a}}$ série do ensino médio. Estimamos pelo método dos Mínimos Quadrados o logaritmo da proficiência em função de quando os alunos começaram os estudos, e de variáveis características dos mesmos, dos professores, dos diretores e da escola.

A Tabela 12 mostra os resultados das estimações considerando, separadamente, os alunos da $4^{\mathrm{a}}$ e da $8^{\mathrm{a}}$ séries do ensino fundamental e da $3^{\mathrm{a}}$ série do ensino médio. Os resultados mostram que os alunos da $4^{\mathrm{a}}$ série do ensino fundamental que começaram a estudar na pré-escola tiveram, em média, melhor desempenho no teste de matemática do que os alunos que começaram a estudar a partir da $l^{\text {a }}$ série do ensino fundamental. A estimação mostra que, condicionando pelas características dos alunos, dos professores e das escolas, a influência da pré-escola no desempenho dos alunos da $4^{\text {a }}$ série do ensino fundamental no exame de proficiência em matemática é de 7,5\%.

Essa tabela mostra, ainda, os resultados das estimações considerando os alunos da $8^{\mathrm{a}}$ série do ensino fundamental e os alunos da $3^{\mathrm{a}}$ série do ensino médio. Em ambas os alunos que iniciaram os estudos na pré-escola (a pesquisa não diferencia creche e préescola para essas séries) tiveram desempenho, em média, melhor do que os alunos que ingressaram da $\mathrm{l}^{\mathrm{a}}$ série do ensino fundamental em diante. Notamos também que a influência da pré-escola no desempenho escolar é maior para os alunos do ensino fundamental do que para os alunos do ensino médio. Os resultados indicam que a pré-escola melhora o desempenho escolar dos alunos nos testes de proficiência em $3 \%$ e $1 \%$ na $8^{a}$ série do ensino fundamental e $3^{a}$ série do ensino médio, condicionados pelas características dos alunos, dos professores e das escolas - ambos inferiores à influência da pré-escola no desempenho dos alunos da $4^{\mathrm{a}}$ série.

Assim, nossos resultados mostram que os efeitos da pré-escola diminuem ao longo das séries. Uma possível interpretação para isto é que a pré-escola é mais importante nos ciclos iniciais, quando quase todas as crianças estão na escola. À medida que as crianças avançam nas séries, as menos preparadas vão saindo da escola e a pré-escola passa a não fazer tanta diferença, pelo efeito seleção, como destacamos no caso da conclusão dos ciclos escolares.

3 Para os alunos da $4^{\text {a }}$ série do ensino fundamental, a variável de idade está em anos de idade $(9$ a 15 ou mais), e para os alunos da $8^{\mathrm{a}}$ série do ensino fundamental e $3^{\mathrm{a}}$ série do ensino médio essa variável está em ano de nascimento (1985 a 1991 em diante). 


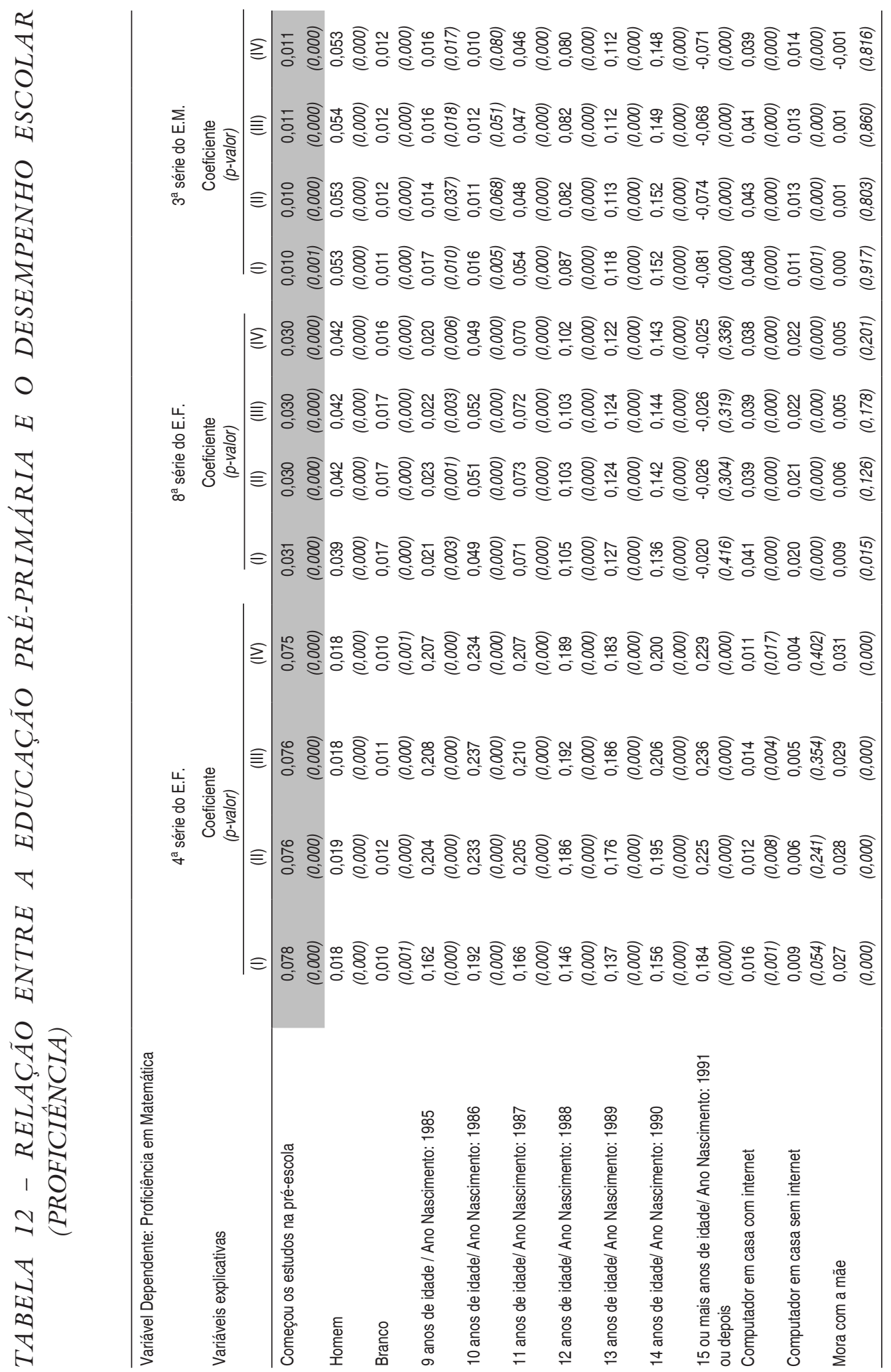




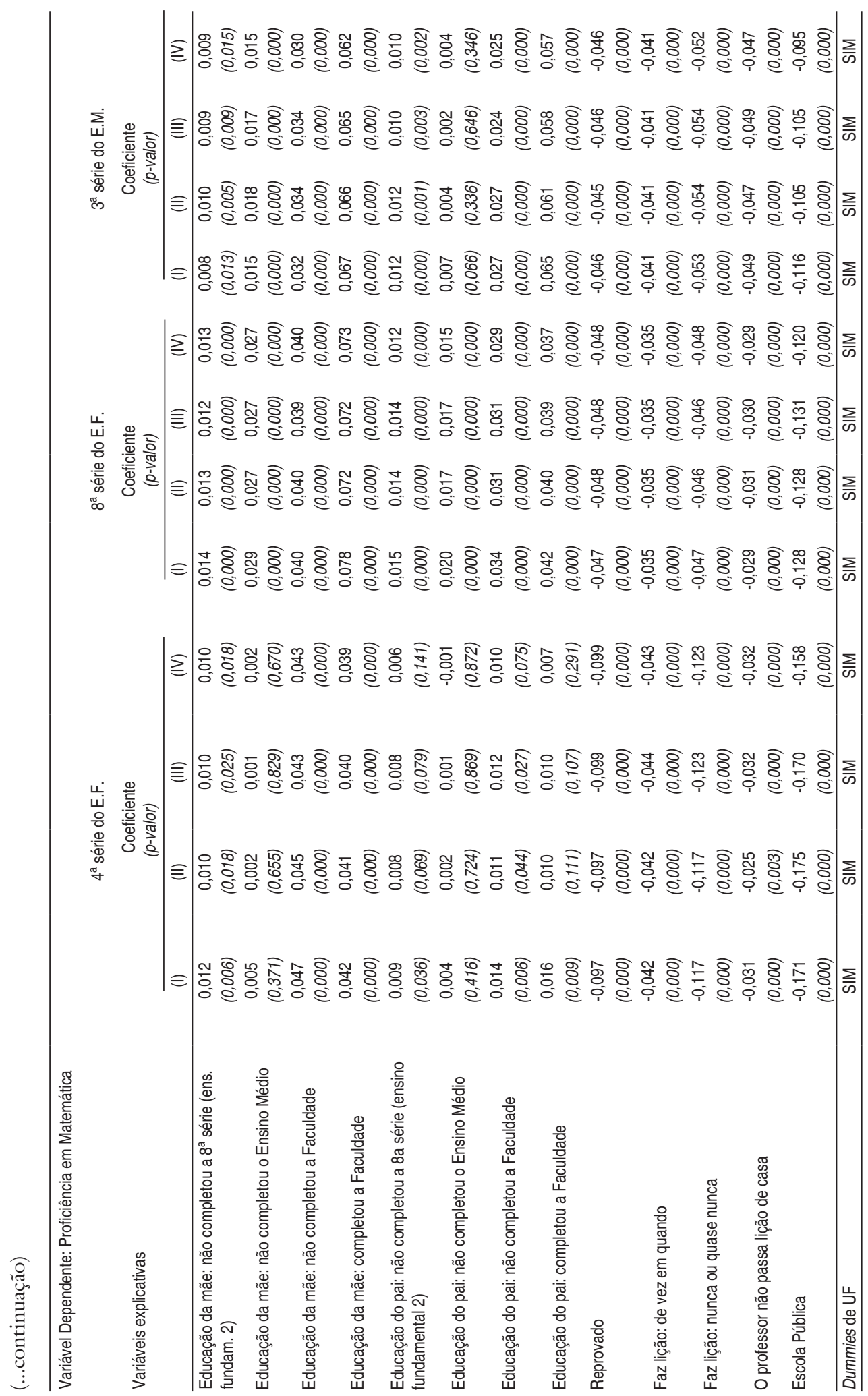




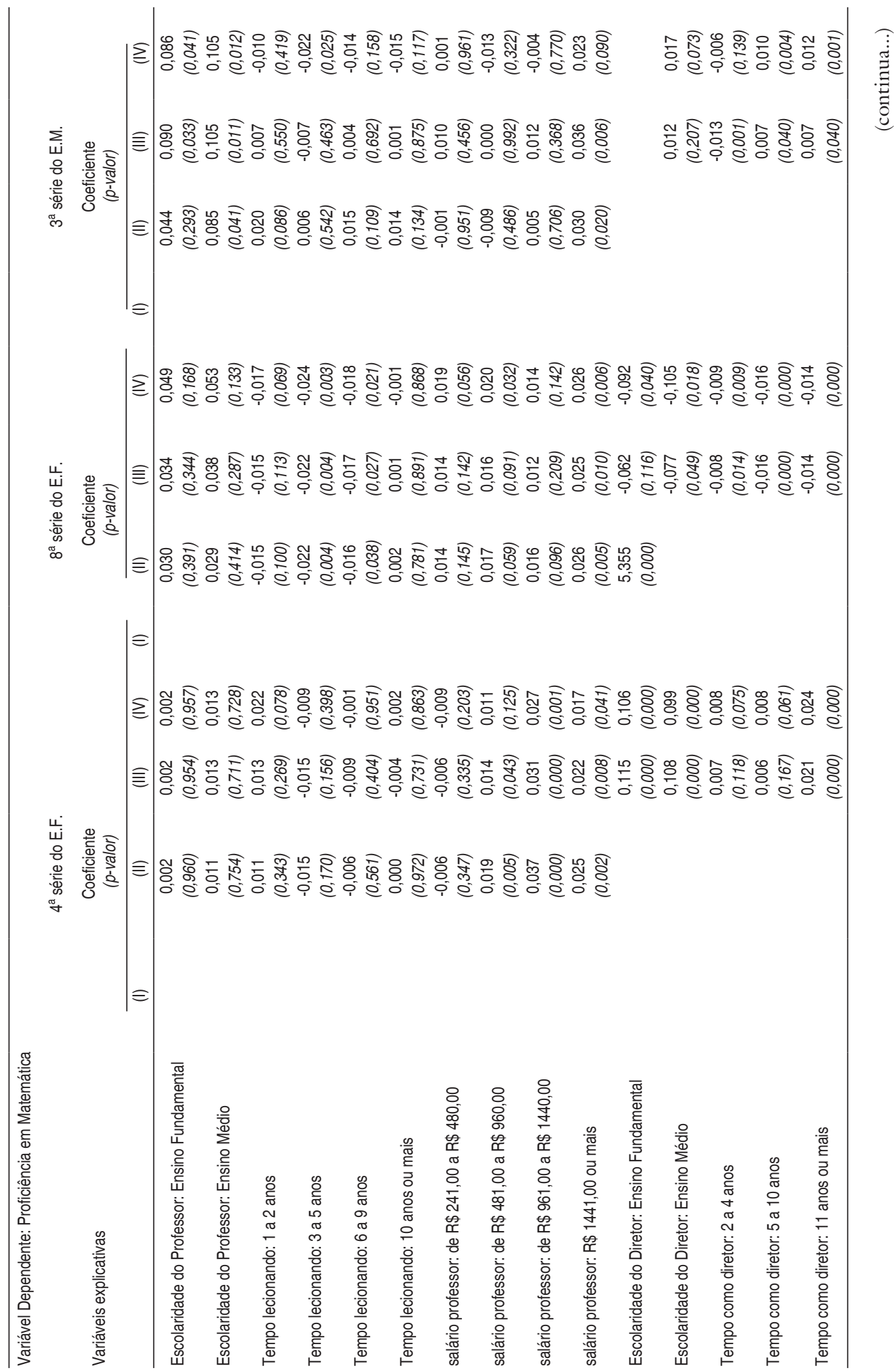




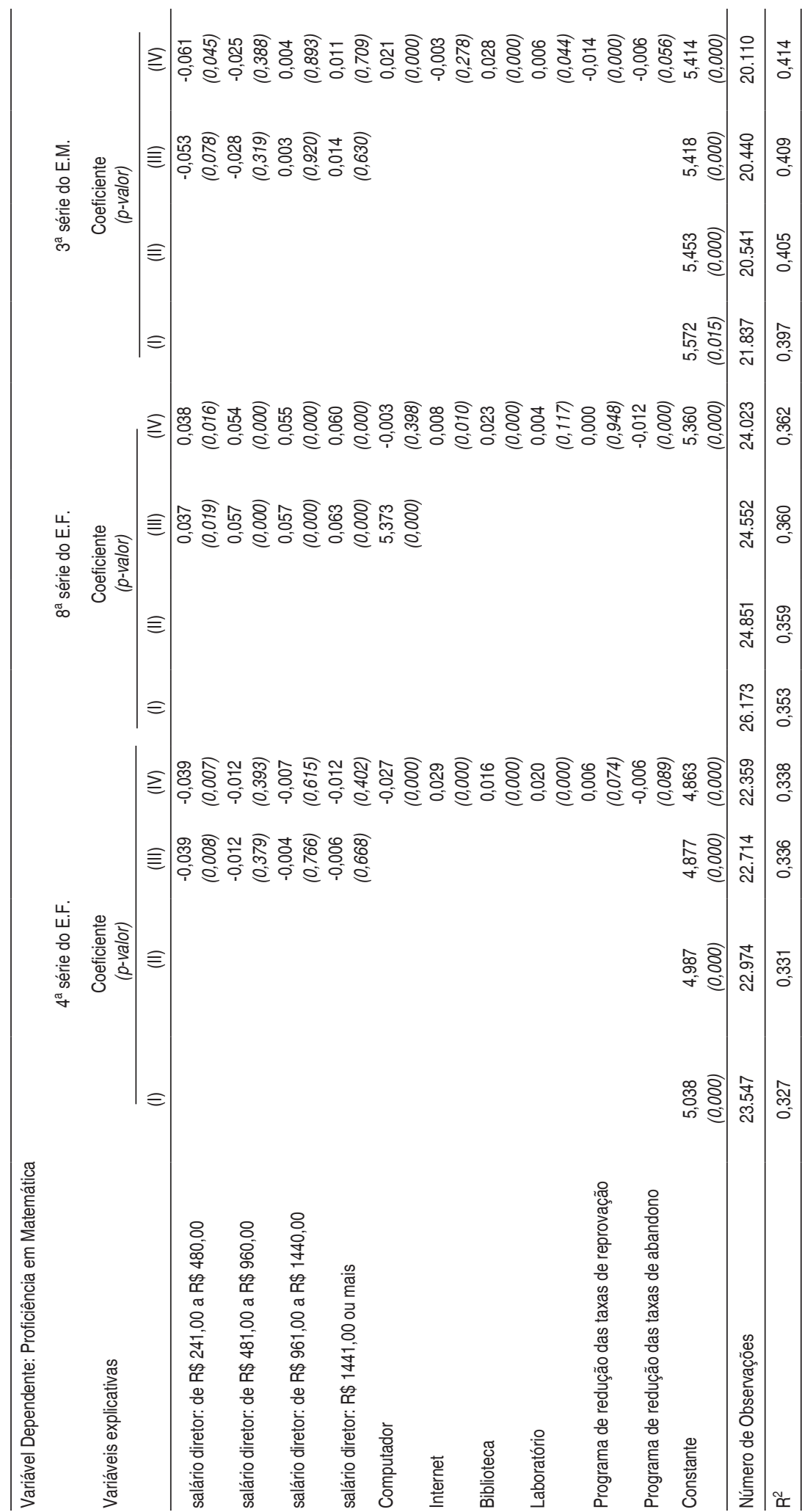


Observamos ainda, que os resultados obtidos da relação entre a educação pré-primária e o desempenho escolar de todas as séries são bastante robustos. Mesmo inserindo ao modelo inicial, que tem apenas as características dos alunos (coluna I), as características dos professores (coluna II), dos diretores (coluna III) e das escolas (coluna IV), o efeito estimado da educação pré-primária sobre o desempenho no exame de proficiência apresentou alteração mínima ou insignificante. Essa pequena variação nos resultados do efeito da educação pré-primária também pode ser interpretada como sendo em função da pouca relevância das variáveis incluídas ao modelo para explicar o desempenho escolar. Isso é ressaltado pelo fato de que a parcela da variância explicada quase não se alterou entre os modelos (I) e (IV).

\section{CONCLUSÃO}

Neste artigo procuramos analisar a importância da educação pré-primária no desenvolvimento do indivíduo. Concluímos que a educação entre 0 e 6 anos de idade tem efeitos socioeconômicos positivos. Os dados da PPV mostram que a educação préprimária tem relação positiva e significante com a conclusão dos ciclos escolares. De acordo com os resultados obtidos, frequentar a creche - iniciar os estudos com idade entre 0 e 3 anos - não é estatisticamente significante para explicar a conclusão nem do ensino fundamental 1 , nem do ensino médio. Por outro lado, frequentar a escola entre 0 e 3 anos de idade tem relação positiva e significante de $13 \%$ e 19\% com a conclusão do ensino médio e do ensino universitário, respectivamente. Portanto, a creche tem relação mais forte com os níveis educacionais mais elevados.

Com relação à Pré-escola, os resultados indicam que frequentar a escola entre 4 e 6 anos de idade tem relação positiva e significante com a conclusão dos quatro ciclos. Frequentar a pré-escolar aumenta a probabilidade de concluir o ensino fundamental 1 , o ensino fundamental 2, o ensino médio e o ensino universitário em $4 \%, 18 \%$, $24 \%$ e $5,5 \%$, respectivamente, mesmo quando controlamos pela educação dos pais. Além disso, observamos que o efeito marginal da creche é muito maior sobre a conclusão do ensino universitário do que o efeito marginal da pré-escola, enquanto, o efeito marginal da pré-escola é maior do que o efeito marginal da creche na conclusão do ensino médio.

Como resultado da sua relação com a conclusão dos ciclos, verificamos que a educação pré-primária tem relação positiva e significante com a escolaridade média (medida em anos de estudo completos). Além disso, verificamos que a pré-escola tem relação positiva e significante com a renda do trabalho principal. As pessoas que iniciaram os estudos com idade entre 4 e 6 anos ganham, em média, salário 
mais elevado que os demais. A relação da creche com a renda, apesar de positiva, não é estatisticamente significante. Segundo as estimações, a pré-escola aumenta a escolaridade em 1,6 anos e a renda dos indivíduos em 16\%, independentemente do seu impacto na educação.

Por fim, analisamos a relação entre a educação pré-primária e o desempenho escolar dos alunos da $4^{\mathrm{a}}$ e da $8^{\mathrm{a}}$ séries do ensino fundamental e da $3^{\mathrm{a}}$ série do ensino médio, medido por exames de proficiência. Os dados do SAEB realizados em 2003 indicam uma relação positiva e significante entre desempenho escolar desses alunos e o início dos estudos. Os resultados indicam que a pré-escola melhora o desempenho escolar dos alunos, medido por testes de proficiência, em 7,5\%, 3\% e 1\% na $4^{\mathrm{a}}$ e na $8^{a}$ séries do ensino fundamental e na $3^{\text {a }}$ série do ensino médio, condicionados pelas características dos alunos, dos professores e das escolas.

Dessa forma, concluímos que a educação pré-primária tem relação positiva com o capital humano dos indivíduos que a frequentam.

\section{REFERENCIAS}

BEHRMAN, J.; CHENG, Y.; TODD, P. Evaluating pre-school programs when length of exposure to the program varies: a nonparametric approach. Review of Economics and Statistic, v. 86, n. 1, p. 108-132, 2004.

BERGER, L.; PAXSON, C.; WALDFOGEL, J. Income and child development. 2005. (Unpublished manuscript).

BERLINSKI, S.; GALIANI, S. The effect of a large expansion of pre-primary school facilities on preschool attendence and maternal employment. 2005. Unpublished manuscript.

; GERTLER, P. Public pre-primary schooling and primary school performance. 2005. Unpublished manuscript.

. The effect of pre-primary education on primary school performance. EconPapers, Feb. 2006.

BLAU, D. M. The effect of income on child development. Review of Economics and Statistic, v. 81, n. 2, p. 261-276, 1999.

CARNEIRO, P.; HECKMAN, J. Human capital policy. Cambridge, MA: National Bureau of Economic Research, 2003. (Working Paper, 9495).

.; CUNHA, F.; HECKMAN J. J. Interpreting the evidence of family influence on child development. ECONOMICS OF EARLY CHILDHOOD CONFERENCE, Minneapolis Fed, Oct. 2003. 
CUNHA, F.; HECKMAN, J.; LOCHNER, L.; MASTEROV, D. Interpreting the evidence on life cycle skill formation. Cambridge, MA, NBER, 2005. (Working Paper, 11331).

CURRIE, J.; THOMAS, D. Early test score, socioeconomic status and future outcomes. Cambridge, MA: National Bureau of Economic Research, 1999. (Working Paper, 6943).

. Early childhood education programs. Journal of Economic Perspectives, 145, p.213-238, 2001.

GARCES, E.; THOMAS, D.; CURRIE, J. Longer-term effects of head start. The American Economic Review, v. 92, n. 4, p. 999-1012, 2002.

GERTLER, P. J.; FERNALD, L.C. The medium term impact of oportunidades on child development in rural areas. 2004. Unpublished manuscript.

HECKMAN, James J. Lessons from the technology of skill formation. NBER, 2005. (Working Paper, 11142).

PAXSON, C.; SCHADY, N. Cognitive development among young children in Ecuador: the holes of wealth, health and parenting. Washington, D.C., Policy Research World Bank, 2005. (Working Paper, n. 3605).

ROBERTSON, D.; SYMONS, J. Do peer groups matter? Peer group versus schooling effects on academic attainment. Economica, 70, p. 31-53, 2003.

SCHADY, N. Early childhood development in Latin America and the Caribbean. World Bank Policy Research, March 2006. (Working Paper, 3869).

TAYLOR, B.; DEARING, E.; MCCARTNEY, K. Incomes and outcomes in early childhood. Journal of Human Resources, v. 39, n. 4, p. 980-1007, 2004. 


\section{ANEXO A}

TABELA A.I - ESTATÍSTICAS DESCRITIVAS DAS VARIÁVEIS DOS MODELOS DE EDUCAÇÃO

\begin{tabular}{|c|c|c|c|c|c|}
\hline Variáveis & Obs. & Média & Erro Padrão & Min & Max \\
\hline Ensino Fundamental 1 & 3.886 & 0,912 & 0,283 & 0 & 1 \\
\hline Ensino Fundamental 2 & 3.886 & 0,642 & 0,480 & 0 & 1 \\
\hline Ensino Médio & 3.886 & 0,467 & 0,499 & 0 & 1 \\
\hline Ensino Universitário & 3.886 & 0,148 & 0,356 & 0 & 1 \\
\hline Anos de estudo completos & 3.886 & 8,943 & 4,164 & 0 & 16 \\
\hline Creche & 3.842 & 0,017 & 0,129 & 0 & 1 \\
\hline Pré-escola & 3.842 & 0,263 & 0,440 & 0 & 1 \\
\hline Homem & 3.886 & 0,493 & 0,500 & 0 & 1 \\
\hline Branco & 3.886 & 0,691 & 0,462 & 0 & 1 \\
\hline Idade & 3.886 & 36,208 & 10,525 & 21 & 65 \\
\hline Educação da mãe: Nenhuma & 3.886 & 0,043 & 0,202 & 0 & 1 \\
\hline Educação da mãe: Ensino Fundamental 1 & 3.886 & 0,702 & 0,457 & 0 & 1 \\
\hline Educação da mãe: Ensino Fundamental 2 & 3.886 & 0,118 & 0,322 & 0 & 1 \\
\hline Educação da mãe: Ensino Médio & 3.886 & 0,105 & 0,307 & 0 & 1 \\
\hline Educação da mãe: Ensino Superior & 3.886 & 0,032 & 0,176 & 0 & 1 \\
\hline Educação do pai: Nenhuma & 3.886 & 0,041 & 0,199 & 0 & 1 \\
\hline Educação do pai: Ensino Fundamental 1 & 3.886 & 0,686 & 0,464 & 0 & 1 \\
\hline Educação do pai: Ensino Fundamental 2 & 3.886 & 0,110 & 0,313 & 0 & 1 \\
\hline Educação do pai: Ensino Médio & 3.886 & 0,090 & 0,286 & 0 & 1 \\
\hline Educação do pai: Ensino Superior & 3.886 & 0,073 & 0,260 & 0 & 1 \\
\hline Idade que começou a trabalhar & 3.886 & 15,383 & 5,034 & 5 & 54 \\
\hline Mãe trabalhava aos 15 anos de idade & 3.886 & 0,380 & 0,485 & 0 & 1 \\
\hline Vivia mãe aos 15 anos de idade & 3.886 & 0,932 & 0,252 & 0 & 1 \\
\hline Área urbana & 3.886 & 0,914 & 0,281 & 0 & 1 \\
\hline
\end{tabular}

Fonte: PPV. Elaboração própria. 


\section{TABELA A.2 - ESTATÍSTICAS DESCRITIVAS DAS VARIÁVEIS DOS MODELOS DE RENDA}

\begin{tabular}{lccccr}
\hline Variáveis & Obs. & Média & Erro Padrão & Min & Max \\
\hline Renda em log & 1.836 & 6,362 & 1,083 & 2,708 & 9,909 \\
Creche & 1.836 & 0,019 & 0,138 & 0 & 1 \\
Pré-escola & 1.836 & 0,319 & 0,466 & 0 & 1 \\
Homem & 1.836 & 0,568 & 0,495 & 0 & 1 \\
Branco & 1.836 & 0,685 & 0,465 & 0 & 1 \\
Idade & 1.836 & 34,345 & 9,191 & 21 & 64 \\
Educação da mãe: Nenhuma & 1.836 & 0,036 & 0,185 & 0 & 1 \\
Educação da mãe: Ensino Fundamental 1 & 1.836 & 0,660 & 0,474 & 0 & 1 \\
Educação da mãe: Ensino Fundamental 2 & 1.836 & 0,130 & 0,337 & 0 & 1 \\
Educação da mãe: Ensino Médio & 1.836 & 0,134 & 0,341 & 0 & 1 \\
Educação da mãe: Ensino Superior & 1.836 & 0,040 & 0,197 & 0 & 1 \\
Educação do pai: Nenhuma & 1.836 & 0,024 & 0,152 & 0 & 1 \\
Educação do pai: Ensino Fundamental 1 & 1.836 & 0,667 & 0,471 & 0 & 1 \\
Educação do pai: Ensino Fundamental 2 & 1.836 & 0,121 & 0,326 & 0 & 1 \\
Educação do pai: Ensino Médio & 1.836 & 0,103 & 0,304 & 0 & 1 \\
Educação do pai: Ensino Superior & 1.836 & 0,086 & 0,280 & 0 & 1 \\
Idade que começou a trabalhar & 1.836 & 15,777 & 4,739 & 5 & 46 \\
Mãe trabalhava aos 15 anos de idade & 1.836 & 0,378 & 0,485 & 0 & 1 \\
Vivia mãe aos 15 anos de idade & 1.836 & 0,941 & 0,236 & 0 & 1 \\
Área urbana & 1.836 & 0,919 & 0,274 & 0 & 1 \\
\hline & & & & 0 \\
\hline
\end{tabular}

Fonte: PPV. Elaboração própria. 